This document is the accepted manuscript version of the following article:

Abbott, D. F., Pittkowski, R. K., Macounová, K., Nebe1, R., Mare11i, E., Fabbri, E., ... Schmidt, T. J. (2019). Design and synthesis of Ir/Ru pyrochlore catalysts for the oxygen evolution reaction based on their bulk thermodynamic properties. ACS Applied Materials and Interfaces, 11(41), 37748-37760. https://doi.org/10.1021/acsami.9b13220

\title{
Design and Synthesis of Ir/Ru Pyrochlore Catalysts for the Oxygen Evolution Reaction Based on
}

Their Bulk Thermodynamic Properties

Daniel F. Abbott ${ }^{\mathrm{a}}$, Rebecca K. Pittkowsk,j Kateřina Macounovå, Roman Nebę, Elena Marelfịc, Emiliana Fabbria, Ivano E. Castelli ${ }^{*}$,Petr Krtil ${ }^{b^{*}}$, Thomas J. Schmidt ${ }^{\mathrm{a}, \mathrm{e}^{*}}$

${ }^{a}$ Electrochemistry Laboratory, Paul Scherrer Institut, CH-5232 Villigen PSI, Switzerland

bJ. Heyrovský Institute of Physical Chemistry of the Czech Academy of Sciences, Dolejškova 3, 18223, Prague, Czech Republic

'Laboratory for Multiscale Materials Experiments, Paul Scherrer Institut, CH-5232 Villigen PSI, Switzerland

${ }^{d}$ Department of Energy Conversion and Storage, Technical University of Denmark, DK-2800 Kgs. Lyngby, Denmark

eLaboratory of Physical Chemistry, ETH Zürich, CH-8093 Zürich, Switzerland

*Corresponding authors:

Thomas J. Schmidt (PSI): thomasjustus.schmidt@psi.ch

Petr Krtil (HIPC): petr.krtil@jh-inst.cas.cz

Ivano E. Castelli (DTU): ivca@dtu.dk

Abstract

Density Functional Theory (DFT) has proven to be an invaluable and effective tool for identifying highly active electrocatalysts for the oxygen evolution reaction (OER). Herein we take a computational approach in order to first identify a series of rare-earth pyrochlore oxides based on Ir and Ru as potential OER catalysts. The DFT-based phase diagrams, Pourbaix diagrams (E vs. $\mathrm{pH}$ ), projected density of states (PDOS), and band energy diagrams were used to identify prospective OER catalysts based on rare earth Ir and Ru pyrochlores. The predicted materials were synthesized using the spray-freeze freeze-drying approach to afford nanoparticulate oxides conforming to the pyrochlore structural type $\mathrm{A}_{2} \mathrm{~B}_{2} \mathrm{O}_{7}$ where $\mathrm{A}=\mathrm{Nd}, \mathrm{Gd}$, or $\mathrm{Yb}$ and $\mathrm{B}=\operatorname{Ir}$ or $\mathrm{Ru}$. In agreement with the computed Pourbaix diagrams, the materials were found to be moderately stable under OER conditions. All prepared materials show higher stability as compared to the benchmark $1 \mathrm{IO}_{2}$ catalyst and the OER mass activity of $\mathrm{Yb}_{2} \mid \mathrm{I}_{2} \mathrm{O}_{7}$ and the ruthenate pyrochlores $\left(\mathrm{Nd}_{2} \mathrm{Ru}_{2} \mathrm{O}_{7}, \mathrm{Gd}_{2} \mathrm{Ru}_{2} \mathrm{O}_{7}\right.$, and $\left.\mathrm{Yb}_{2} \mathrm{Ru}_{2} \mathrm{O}_{7}\right)$ were also found to exceed that of the benchmark $1 \mathrm{rO}_{2}$ catalyst. We find that the OER activity of each pyrochlore series 
(i.e. iridate or ruthenate) generally improves as the size of the A-site cation decreases, indicating that maintaining control over the local structure can be used to influence the electrocatalytic properties.

\author{
Keywords \\ Oxygen evolution, pyrochlore, DFT, iridium, ruthenium, lanthanide
}

\title{
Introduction
}

Hydrogen production via the electrochemical splitting of water (i.e. water electrolysis) is expected to play a key-role in large-scale storage and conversion of renewable energy storage and conversion, particularly when coupled with intermittent renewable energy sources, e.g. wind and solar photovoltaic power. ${ }^{1}$ As has been shown, hydrogen can be easily transferred and stored within the natural gas networks, i.e. Power-to-Gas, thereby enabling the distribution of renewable energy to the heat and transport sectors as well. ${ }^{2-3}$ For such applications, polymer electrolyte electrolyzer cells (PEEC) are particularly attractive systems given their innate ability to generate hydrogen at high purity (>99.99\% after drying) and relatively high pressure (up to 350 bar). They can also operate at high current densities and provide exceptional system flexibility. ${ }^{4-5}$ Several large-scale PEEC pilot plants in the MW range are currently being tested ${ }^{6-7}$ and many experts predict that PEEC will be strongly preferred over competing electrolysis systems (e.g. alkaline, solid oxide) within the next 10 years. ${ }^{2}$ Currently, however, the predicament of using scarce and expensive precious metal catalysts poses a significant hurdle to overcome before PEECs can be made into a viable option for energy storage and conversion on a global GW-scale. The development of more feasible electrocatalysts therefore remains as a critical task to be accomplished. ${ }^{8}$

The strong corrosive environment and high operating potentials required for oxygen evolution encountered in PEECs invoke great restrictions on the choice of suitable catalyst materials, essentially limiting the choices to the highly stable noble metals and their oxides (e.g. $\mathrm{IrO}_{2}$ and $\mathrm{RuO}_{2}$ ). While great reductions in the Pt metal loading at the hydrogen evolving cathode have already been achieved ${ }^{5}$, the high precious metal loadings required at the anode to catalyze the kinetically-hindered oxygen evolution reaction (OER) pose a more considerable challenge. Given the absence of stable, alternative catalysts suitable for acid media, one needs to adopt strategies to improve the feasibility of the catalysts based on Ir and Ru despite their scarcity and high costs. There are several strategies to achieve this goal. In particular, one may opt to reduce the total metal loading at the anode while maintaining high catalyst activity, or alternatively one may aim at improving of the catalyst stability. In general, the most common strategies employed typically consider increasing the electrochemically active surface 
area by reducing the particle size or supporting the catalyst on a high surface area support, ${ }^{9-10}$ or by substitution of the noble metal with more abundant metals to create mixed-metal oxides. ${ }^{11-14}$ In the latter case, the mixed-metal oxides containing Ru and/or Ir need to show sufficient conductivity and they need also to represent the most thermodynamically stable phase (within the given system) at the conditions imposed by the oxygen evolution process.

The pyrochlore family of oxides conforming to the general formula $A_{2} B_{2} O_{7}$ represents a promising class of candidate materials for the replacement of the conventional Ru and Ir oxide OER catalysts. The cubic pyrochlore structure features two types of cationic sites ordered along the (110) direction, where a $\left[\mathrm{Ru}-\mathrm{O}_{6}\right]$ or $\left[\mathrm{Ir}-\mathrm{O}_{6}\right]$ network is stabilized by a divalent $\left(\right.$ e.g $\left.\mathrm{Pb}^{2+}\right)$ or trivalent (e.g. $\mathrm{Bi}^{3+}$ or rare earth elements) cation in the A-site. ${ }^{15}$ Aside from the main application of pyrochlores connected with their particularly interesting magnetic properties ${ }^{16-17}$, their electrocatalytic properties in the oxygen reduction ${ }^{18-19}$ and evolution ${ }^{14-15,19-22}$ reactions have also been explored. Considering that a large number of pyrochlore oxides could be produced from the various A-site and B-site combinations, taking a rational approach to the design of the catalyst becomes rather critical to identify those that possess the necessary physical and electronic properties to make a good catalyst. Computer simulations have been extremely helpful in guiding the search for novel materials as well as predicting the results of experiments. ${ }^{23-25}$ The increase of computational power and the improvements in methods and in accuracy ${ }^{26-27}$ have contributed to making computational results more reliable and the theoretical design of novel materials possible. Recent studies have utilized DFT calculations to rationalize the phase stability and the $\mathrm{pH}$-dependent electrochemical stability of perovskite ${ }^{28}$ and pyrochlore ${ }^{14}$ catalysts for the OER with great success, however, so far this approach has not been implemented as a screening method for identifying promising OER candidate materials from the start.

In the present study we aim to identify novel pyrochlore materials for the oxygen evolution reaction (OER) based on their bulk thermodynamic properties by following a high-throughput, DFTbased approach. Essentially, we aim to predict whether the materials will be phase stable (i.e. can they be synthesized?), conductive (will they have the conductivity required by a catalyst?), and phase stable in solution (will they dissociate at the $\mathrm{pH} /$ electrochemical potential values imposed by water electrolysis?). Although many DFT-based studies often focus on the catalyst surface, the bulk properties of the material are often overlooked and it is critical to recognize that they are equally important to its applicability as a catalyst. In this study we identify potential Ir and Ru-based rare-earth pyrochlore oxide candidate materials, in which the A-site is occupied by a lanthanide earth metal and the B-site contains either Ru or Ir, by means of calculated phase diagrams, Pourbaix diagrams (phase stability as a function of electrode potential $(\mathrm{E})$ and $\mathrm{pH}$ ), and electronic properties (band diagrams and projected density of states (PDOS)). In addition, currently there exist only a few reports detailing the 
synthesis of the target rare-earth pyrochlores. The materials are typically prepared via solid state synthesis at exceedingly high temperatures, which inevitably results in the growth of crystallites in the micrometer range. Herein, we report the synthesis of nano-particulate rare-earth pyrochlore oxides $\left(\mathrm{A}_{2} \mathrm{~B}_{2} \mathrm{O}_{7}\right.$, where $\mathrm{A}=\mathrm{Nd}, \mathrm{Gd}, \mathrm{Yb}$ and $\mathrm{B}=$ Ir or $\left.\mathrm{Ru}\right)$ and their application as OER catalysts in acidic media. While we observe that some materials undergo preferential dissolution of the A/B-site cations with potential-step cycling, we find that the short-term stability and precious metal mass activity of the pyrochlores generally surpass that of the benchmark $\mathrm{IrO}_{2}$ catalyst.

\section{Computational and Experimental Details}

Density Functional Theory Calculations

All simulations were performed in the framework of Density Functional Theory (DFT) using the Quantum Espresso package ${ }^{29}$ powered by AiiDA ${ }^{30}$. The pseudopotentials from the Standard Solid State Pseudopotential library (SSSP accuracy) were used. ${ }^{27,}{ }^{31}$ All investigated structures have been fully relaxed using $\mathrm{PBEso}{ }^{32}$ as exchange-correlation functional adding a Hubbard $+\mathrm{U}$ correction of $5 \mathrm{eV}$ applied to the orbitals of the rare-earth element. A uniform $6 \times 6 \times 6$ k-point mesh and a MarzariVanderbilt smearing of 0.02 Ry have been used. A path passing through all high-symmetry points has been chosen for the band structures calculations. ${ }^{33}$

A required step in any targeted computational screening project is the definition of few, easy to calculate descriptors which link the calculated microscopic properties with the macroscopic quantities that can be measured in experiments and that are required for the material to be a candidate for the target application.[67] To be used as an OER catalyst, a material should be stable against phase separation in aqueous solution at a given $\mathrm{pH}$ (i.e. be intrinsically stable under OER conditions) and also to be conductive. The evaluation of the stability is performed using the phase diagram module implemented in the Atomic Simulation Environment (ASE) ${ }^{34}$ by means of the convex hull and the Pourbaix diagrams. The former compares the total energy of the pyrochlore phase with the energies of the possible known competing phases taken from the Materials Project database. ${ }^{35}$ The latter, instead, provides an understanding of the stability in water as a function of $\mathrm{pH}$ and electrochemical potential by comparing the total energy of the candidate material with not only the energies of the solid competing phases (calculated by DFT), but also with the dissolution energies for the solution-based phases measured with experiments. ${ }^{36-37}$ In this manner it extends the convex hull calculations by including the dissolution energies to predict the stable phases under OER conditions. More details about the method can be found in the literature. ${ }^{38-39}$ This approach has been recently used to investigate the stability of Ir-pyrochlores and Ru-perovskites for the OER ${ }^{14,28}$ as well as to identify light-harvesting materials for photoelectrochemical water splitting. ${ }^{40}$ It is not trivial to 
determine the conductivity of a material using DFT. For the purpose of this work, we consider a material to be "conductive" if the calculated band structure shows bands crossing the Fermi level. Similar information can also be obtained from the projected density of states (PDOS), which have also been calculated.

Computational screening of the rare-earth pyrochlores was limited to those containing relatively abundant and inexpensive lanthanide metals (i.e. $\mathrm{La}, \mathrm{Ce}, \mathrm{Pr}, \mathrm{Nd}, \mathrm{Sm}, \mathrm{Gd}$, or $\mathrm{Yb}$ ) in the A-site while containing either Ru or Ir in the B-site. Pyrochlores containing mixed combinations of A-site or B-site metals (e.g. $A_{x}^{\prime} A_{2-x} B_{y}^{\prime} B_{2-y} O_{7}$ ) were not considered at this time. In addition, rare-earth pyrochlores containing scarce or expensive lanthanide metals (e.g. Eu, Dy, Ho, etc.) were excluded from the screening process.

\section{Chemicals}

Ruthenium nitrosyl nitrate ( $\mathrm{Ru}(\mathrm{NO})\left(\mathrm{NO}_{3}\right)_{3}, 31.3$ at.\% Ru, Alfa Aesar) and iridium (III) acetate $\left(\operatorname{Ir}\left(\mathrm{OOCCH}_{3}\right)_{3}, 48.8\right.$ at.\% Ir, Chempur) were used as the source of ruthenium and iridium, respectively. Ytterbium acetate $\left(\mathrm{Yb}\left(\mathrm{OOCCH}_{3}\right) \cdot \times \mathrm{H}_{2} \mathrm{O}\right)$, gadolinium acetate $\left(\mathrm{Gd}\left(\mathrm{OOCCH}_{3}\right)_{3} \cdot \mathrm{xH}_{2} \mathrm{O}\right)$, and neodymium acetate $\left(\mathrm{Nd}\left(\mathrm{OOCCH}_{3}\right) \cdot \mathrm{x} \mathrm{H}_{2} \mathrm{O}\right)$ (all Sigma Aldrich, 99.9\%) were used as the sources of the rare-earth elements. The actual crystal water content, $x$, in rare-earth metal acetates was determined by thermal analysis using a SetSys Evolution system (Setaram) coupled with a quadrupole mass spectrometer (QMG 700, Pfeiffer) by SuperSonic system (Setaram). Decomposition of the rare-earth metal acetates was performed by heating the powders in a temperature range of $30-1000{ }^{\circ} \mathrm{C}$ (at $10^{\circ} \mathrm{C} \mathrm{min}^{-1}$ ) in an open alumina crucible under inert atmosphere (argon, $60 \mathrm{~mL} \mathrm{~min}{ }^{-1}$ ). Evolved gas analysis data were collected in multiple-ion detection mode (MID) as intensity (A) of individual selected fragments. Values of $\mathrm{m} / \mathrm{z}$ (mass-to-charge ratios) were pre-selected to: $12,16,17,18,28$ and 44 . The actual crystal water content was found to be $x=4.0$ in the case of ytterbium acetate, 2.8 for gadolinium acetate, and 1.1 in the case of neodymium acetate.

\section{Material preparation}

The theoretically predicted pyrochlore materials were prepared using the spray-freeze freezedrying approach..$^{41-42}$ In brief, precursor solutions containing the transition metal (Ru/Ir) and rare-earth metal $(\mathrm{Nd}, \mathrm{Gd}, \mathrm{Yb})$ sources were prepared by directly dissolving the corresponding nitrosyl nitrate and acetate salts in Milli-Q quality deionized water. The total metal concentration in each stock solution was kept at $8 \mathrm{mM}$ and each solution was stirred for at least 30 minutes to ensure complete mixing. Preparation of the ice precursors and further mixing of the cations was achieved by spraying $100 \mathrm{~mL}$ 
of stock solution into ca. $2 \mathrm{~L}$ of liquid nitrogen. The resulting ice precursor was then freeze-dried using a FreeZone Triad Freeze Dry System 7400030 (Labconco) at reduced pressure (1 Pa) according to the subsequent temperature protocol. First, the ice precursor was precooled to $-30{ }^{\circ} \mathrm{C}$ while the cooling chamber was evacuated. The temperature was then gradually increased as follows: $-30^{\circ} \mathrm{C}(2 \mathrm{~h}),-25^{\circ} \mathrm{C}$ $(5 \mathrm{~h}),-20{ }^{\circ} \mathrm{C}(4 \mathrm{~h}),-15{ }^{\circ} \mathrm{C}(6 \mathrm{~h}),+30{ }^{\circ} \mathrm{C}(4 \mathrm{~h})$. The dried precursor was removed from the freeze-dryer and immediately pre-annealed at $300^{\circ} \mathrm{C}$ in a muffle furnace for 30 minutes. Additional calcination was performed in a tube furnace under air at temperatures ranging between $600^{\circ} \mathrm{C}$ and $1200^{\circ} \mathrm{C}$. The exact calcination temperature and time was varied (12 to $24 \mathrm{~h}$ ) in order to obtain single phase pyrochlore materials. The $\mathrm{IrO}_{2}$ standard (BET surface area $\left(\mathrm{SA}_{\mathrm{BET}}\right)=30 \mathrm{~m}^{2} \mathrm{~g}^{-1}$ ) was synthesized via modified Adam's fusion method. Details on the synthesis and full characterization (e.g. physical and electrochemical) of this sample can be found in the references..$^{9,14}$

\section{Physical characterization}

The crystallinity and phase purity of the synthesized materials were analyzed by powder X-ray diffraction (XRD). The diffraction patterns were recorded using a Rigaku Miniflex 600 powder X-ray diffractometer with $\mathrm{Cu} \mathrm{K}_{\alpha}$ radiation operating at $30 \mathrm{kV}$ and $10 \mathrm{~mA}$. The unit cell parameters were determined using UnitCellWin software. Morphology and particle size of the prepared samples was analyzed using a Hitachi S4800 scanning electron microscope (SEM) equipped with a Nanotrace EDX detector (Thermo Electron). The average sample composition was determined by energy dispersive $x-$ ray spectroscopy (EDX) measured at accelerating voltage of $25 \mathrm{keV}$. In addition, the oxygen stoichiometry was determined by thermogravimetric reduction ${ }^{43}$ on a Netzsch STA 449C instrument coupled with a Pfeiffer vacuum ThermoStar mass spectrometer. The samples were heated up to 1000 ${ }^{\circ} \mathrm{C}\left(2{ }^{\circ} \mathrm{C} / \mathrm{min}\right.$ rate $)$ in a $60 \mathrm{~cm}^{3}$ flow of He with $5 \%$ of $\mathrm{H}_{2}$.

X-ray absorption (XAS) spectra were collected at the SuperXAS beamline of the Swiss Light Source (SLS) (PSI, Villigen, Switzerland). The SLS is a third generation synchrotron, which operates under top up mode at $2.4 \mathrm{GeV}$ electron energy and a current of $400 \mathrm{~mA}$. The incident beam was collimated by a Pt-coated mirror (for measurements at the Ru K-edge) or a Rh coated mirror (for measurements at the Ir $\mathrm{L}_{\| I}$ edge) at $2.5 \mathrm{mrad}$ and monochromatized using a channel-cut $\mathrm{Si}(111)$ monochromator. The beam was subsequently focused with a Rh coated (Ir $\mathrm{L}_{|| \mid}$edge) or a Pt coated (Ru $\mathrm{K}$ edge) toroidal mirror down to $100 \times 100 \mathrm{~mm}$ at the sample position. The beamline energy was calibrated with Pt reference foil to the Pt $L_{\| 1}$ edge position at $11564 \mathrm{eV}$ for the measurement of the Irbased pyrochlores. The ionization chambers were filled at 2 bar of $\mathrm{N}_{2}$ for $\mathrm{Ir}$ measurements in transmission mode and at 1 bar of $\mathrm{N}_{2}$ and 1 bar of Ar for Ru. The SuperXAS beamline ${ }^{44}$ allows for the rapid acquisition of spectra which we used to obtain one XAS spectrum per $500 \mathrm{~ms}$, therefore 
generating one spectrum consisting of 120 averaged spectra per minute. The resulting X-ray absorption data were analyzed using the Demeter program package, ${ }^{45-46}$ which included energy calibration (based on the Pt or Ru reference foils), background subtraction, and edge step normalization.

\section{Electrochemical measurements}

The electrochemical oxygen evolution activities of the prepared materials were evaluated in a standard single-compartment three-electrode cell using a rotating disk electrode (RDE) setup (Pine Instruments, U.S.) and a BioLogic VMP-300 potentiostat following the thin-film RDE approach. ${ }^{47}$ All glassware was vigorously cleaned in a solution of $98 \% \mathrm{H}_{2} \mathrm{SO}_{4}$ and $30 \% \mathrm{H}_{2} \mathrm{O}_{2}$, and then boiled in Milli-Q water several times before use. Catalyst ink suspensions were prepared using $10 \mathrm{mg}$ of pyrochlore catalyst, $1.0 \mathrm{~mL}$ of Milli-Q $\mathrm{H}_{2} \mathrm{O}, 4.0 \mathrm{~mL}$ of isopropyl alcohol, and $20 \mu \mathrm{L}$ of $5 \mathrm{wt} \%$ Nafion (Nafion 117, Alfa Aesar) solution. The ink suspensions were sonicated for $30 \mathrm{~min}$ before depositing $10.0 \mu \mathrm{L}$ on a polished glassy carbon disk electrode $\left(0.196 \mathrm{~cm}^{2}\right)$ to give a total catalyst loading of $100 \mu \mathrm{g}_{\mathrm{cat}} \mathrm{cm}^{-2}$. A piece of a gold mesh served as the counter electrode and an $\mathrm{Hg} / \mathrm{HgSO}_{4}$ electrode served as the reference electrode. All potentials reported herein refer to the reversible hydrogen electrode (RHE) scale and have been corrected for the ohmic drop in solution. The $0.1 \mathrm{M} \mathrm{HClO}_{4}$ electrolyte was prepared from $60 \% \mathrm{HClO}_{4}$ (Kanto Chemical Co., Inc.) and was saturated with synthetic air during all measurements. Cyclic voltammograms were recorded in the potential range of $1.0-1.4 \mathrm{~V}$ at $50 \mathrm{mV} \mathrm{s}^{-1}$ in order to avoid any contributions from the OER current until a steady surface capacitance was measured. Subsequently, several cyclic voltammograms were recorded at $10 \mathrm{mV} \mathrm{s}^{-1}$ and were used to calculate the reported surface charge capacitances (See Figure S1a), which were then normalized and used as an internal standard to approximate differences in the electrochemically active surface area (ECSA) among the pyrochlore samples. ${ }^{9}$ It should be noted that an average of the anodic and cathodic capacitance values was used. Oxygen evolution polarization curves are derived from steady-state chronoamperometric measurements, in which the potential was gradually stepped from 1.2 to $1.6 \mathrm{~V}$ while holding for $1 \mathrm{~min}$ at each potential. Electrochemical impedance spectroscopy measurements were recorded in the range from $15 \mathrm{kHz}$ to $1 \mathrm{~Hz}$ with an amplitude of $10 \mathrm{mV}$. Stability measurements were conducted by stepping the potential between 1.0 and $1.6 \mathrm{~V}$ for 500 cycles while holding for $10 \mathrm{~s}$ at each potential. The normalized oxygen evolution current values are based on the current reading at $1.6 \mathrm{~V}$ after every 50 cycles. The stability cycling protocol was interrupted after every 100 cycles in order to record 5 cyclic voltammograms at $50 \mathrm{mV} \mathrm{s}^{-1}$. The last cycle from each series of cyclic voltammograms was then integrated over the entire potential range (1.0-1.4 $\mathrm{V}$ ) in order to calculate the surface capacitance (See Figure S1b), which were then compared to give an approximation of the changes in 
ECSA that can occur over the course of stability cycling. Aliquots of the electrolyte were collected at the end of the stability measurements and were later analyzed by inductively coupled plasma - optical emission spectroscopy (ICP-OES) using a VISTA Pro AX simultaneous CCD spectrometer (Varian Inc.) with ultrasonic sample nebulization for their dissolved metal content (i.e. for $\mathrm{Ir}, \mathrm{Ru}, \mathrm{Nd}, \mathrm{Gd}$, and $\mathrm{Yb}$ ). All electrochemical measurements were repeated at least three times to ensure reproducibility.

\section{Differential Electrochemical Mass Spectrometry:}

The electrodes for differential electrochemical mass spectrometry (DEMS) were prepared by depositing catalyst ink suspensions containing the pyrochlore materials onto Ti-mesh substrates (open area $20 \%$, Goodfellow). The catalyst ink suspensions were prepared by sonicating $20 \mathrm{mg}$ of the pyrochlore catalyst in $4 \mathrm{mLisopropyl} \mathrm{alcohol,} 1 \mathrm{~mL}$ Milli-Q water, and $20 \mu \mathrm{L}$ Nafion for at least $30 \mathrm{~min}$. Exactly $20 \mu \mathrm{L}$ of ink was drop-cast onto the mesh and dried at $80^{\circ} \mathrm{C}$ in air. This procedure was repeated until a surface coverage of $0.5-1 \mathrm{mg} / \mathrm{cm}^{2}$ was obtained. All DEMS experiments were carried out in 0.1 $\mathrm{M} \mathrm{HClO}_{4}$ electrolyte solution prepared by diluting concentrated $\mathrm{HClO}_{4}(70 \%$, Sigma Aldrich, p.a.) either with Milli-Q water or by ${ }^{18} \mathrm{O}$ labeled $\mathrm{H}_{2}{ }^{18} \mathrm{O}$ (98\%, Medical Isotopes Inc., USA). DEMS experiments were carried out in a home-made Kel-F single compartment cell ${ }^{48}$ in a three-electrode set-up using a Ptauxiliary and an Ag pseudo-reference electrode. All potentials were recalculated and are shown on the RHE scale. All experiments were controlled using a PAR 263A potentiostat. The DEMS experimental setup comprises a PrismaPlusTM QMQ220 quadrupole mass spectrometer (Pfeiffer) connected to a HiPace 80 (PMP03941) turbomolecular drag pumping station (Pfeiffer). In the DEMS experiments the electrode was cycled in $\mathrm{H}_{2}{ }^{16} \mathrm{O}$ based $0.1 \mathrm{M} \mathrm{HClO}_{4}$ between 1.06 and $1.56 \mathrm{~V}$ prior each potential step experiment in $\mathrm{H}_{2}{ }^{18} \mathrm{O}$-based $0.1 \mathrm{M} \mathrm{HClO}_{4}$. The DEMS investigations of the oxygen evolution mechanism were performed at $1.36,1.46$, and $1.56 \mathrm{~V}$ vs. RHE.

\section{Results and Discussion}

\section{Density Functional Theory Calculations}

From the theoretically conceived rare-earth pyrochlores included in the screening, several were identified to meet the required combination of phase stability, electrochemical stability, and conductivity needed for OER electrocatalysis. The candidate materials are those conforming to the pyrochlore cubic structure and containing either $\mathrm{Nd}, \mathrm{Gd}$, or $\mathrm{Yb}$ in the A-site and $\mathrm{Ru}$ or Ir in the B-site. An example of the screening tools used to identify the promising candidate materials is shown in Figure 1 for $\mathrm{Gd}_{2} \mathrm{Ir}_{2} \mathrm{O}_{7}$, while the others can be found in the SI (See Figures S2-S6). The descriptors indicate that the pyrochlore phase is found on the convex hull (See Figure 1a and Table S1), indicating that this phase 
is expected to be stable. It has been discussed in the literature that compounds with an energy of around $100 \mathrm{meV} /$ atom above the convex hull, however, also show a good probability of having a synthesis pathway that can turn their metastability into stability ${ }^{49}$ Currently, it not possible to predict the metastability pathway with computational models, therefore the synthesis of metastable materials is required to make sure that a candidate compound has the desired properties. However, the search for novel materials can be much faster as unstable compounds ( $200 \mathrm{meV} / \mathrm{atom}$ ) or those without the desired electronic/electrochemical stability properties are removed at the computational level.

In addition to exhibiting phase stability, we observe that $\mathrm{Gd}_{2} \mid \mathrm{r}_{2} \mathrm{O}_{7}$ pyrochlore does not dissolve in contact with water within the operating potential window and pH range (Figure 1b). Furthermore, the band structure (Figure 1c) shows that several bands cross at the Fermi level and, therefore, the material can be deemed conductive. This information is further reflected in the PDOS (Figure 1d). The PDOS shows that the valence band is formed by the Ir or Ru-d orbitals hybridized with O-2p orbitals for most of the candidate materials (Figure S3). The Ir or Ru-d orbitals also contribute to the conduction band, which in some cases is a hybridization with the rare-earth elements $f$ orbitals. As can be inferred from the band energy diagrams (Figure S2), PDOS diagrams (Figure S3), phase diagrams (Figure S4), and Pourbaix diagrams (cf. Figure 7), only a few materials qualified for the synthesis and experimental testing because only they have the potential to be used as catalysts (Note: the respective diagrams for materials that did not meet these criteria are combined in Figures S5-S6; the PDOS was not calculated for these materials). In particular, it seems that the A-site ion is responsible for creating a stable conductor, since materials with $\mathrm{Nd}, \mathrm{Gd}$, and $\mathrm{Yb}$ are stable and conductive independently of the $\mathrm{B}$ ion (Ir or $\mathrm{Ru}$ ). The phase diagrams, band energy diagrams, and Pourbaix diagrams for the materials that were not chosen for synthesis can be found in Figures S5-S6. Although all of these materials were also predicted to be conductive according to the band energy diagrams, we found that the pyrochlore phase for materials containing $\mathrm{La}, \mathrm{Ce}, \mathrm{Sm}$, or $\mathrm{Pr}$ in the A-site was not predicted to be thermodynamically favorable. In particular, the pyrochlores containing $\mathrm{La}, \mathrm{Ce}$, and $\operatorname{Pr}$ were not selected for synthesis because these materials were predicted to be either metastable or unstable and, in addition, the theoretical Pourbaix diagrams predict that the pyrochlore phase of these systems is not the stable phase under OER conditions (See Figures S5 and S6). On the other hand, the Sm-based pyrochlores were not selected because the total energies of the Ir and Ru pyrochlore phases were predicted to be 144 and $203 \mathrm{meV}$ above the convex hull (Table S1) and therefore we would not expect them to be stable. These materials, however, have been shown to exist in recent publications. ${ }^{16-17,50}$ The existence of these phases is likely a result of the extreme synthesis conditions employed, which can promote a metastability pathway not predicted via computational models. 
Although the DFT techniques are in principle capable of addressing the surface chemistry of the catalytically active materials and describing the OER process, ${ }^{51-52}$ their application to reflect the surface behavior of the pyrochlore-based catalysts is prohibitively difficult. In contrast to the bulk properties, the modelling of lanthanide pyrochlore surfaces is not accessible within a reasonable amount of effort mainly due to the lack of convenient functionals for the $\mathrm{f}$-orbitals of the lanthanides. A convergent description of the relevant adsorbate surface cannot be reached with the available computational resources, therefore any DFT modelling investigations of oxygen evolution activity of these materials would not provide meaningful results. The failure of the theory to provide the convergent surface optimization can be tied down to the complexity of the pyrochlore surfaces that require the 222 or 444 terminations in the most common in this cases, which leads to a dramatic increase in the number of atoms involved compared to bulk calculations which use a 22 atoms unit cell. This limitation is further demonstrated by the absence of theoretical studies on analogous systems in the literature.

a.

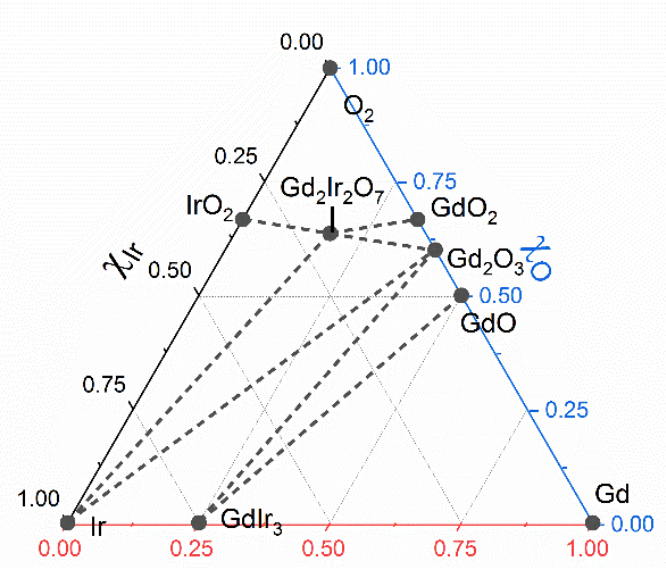

C.

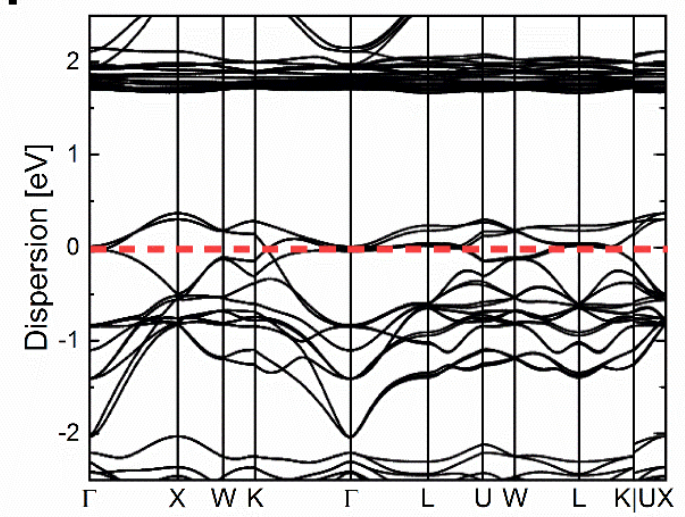

b.

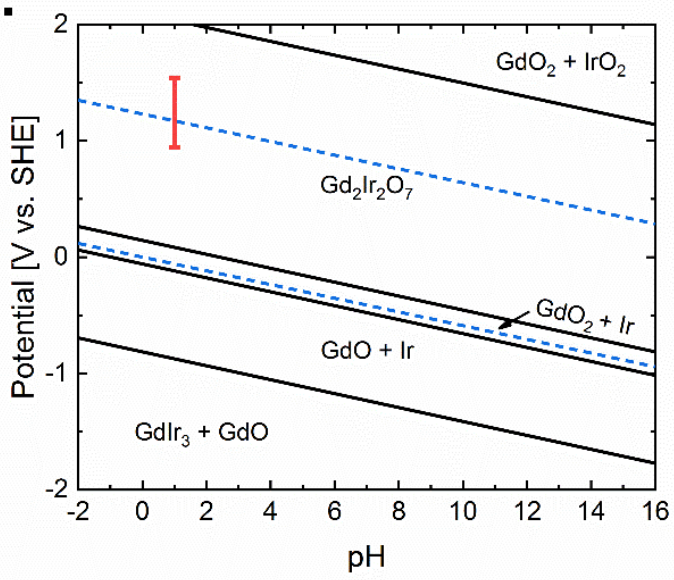

d.

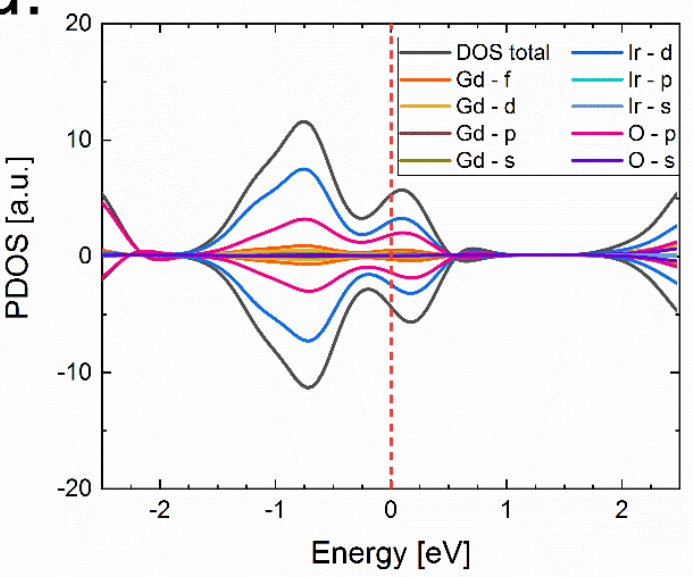


Figure 1. The (a) phase diagram, (b) Pourbaix diagram, (c) band structure diagram, and (d) PDOS diagram for $\mathrm{Gd}_{2} \mathrm{Ir}_{2} \mathrm{O}_{7}$. The Fermi level is indicated by the dashed red lines in the band structure and PDOS diagrams. The dashed blue lines in the Pourbaix diagram indicate the water redox potentials, while the solid red bar indicates the operating E-pH window examined in this study.

\section{Material synthesis and characterization}

The spray-freeze freeze-drying approach was successfully employed to synthesize the following pyrochlore materials: $\mathrm{Nd}_{2} \mathrm{Ru}_{2} \mathrm{O}_{7}, \mathrm{Gd}_{2} \mathrm{Ru}_{2} \mathrm{O}_{7}, \mathrm{Yb}_{2} \mathrm{Ru}_{2} \mathrm{O}_{7}, \mathrm{Nd}_{2} \mid \mathrm{r}_{2} \mathrm{O}_{7}, \mathrm{Gd}_{2} \mathrm{Ir}_{2} \mathrm{O}_{7}$, and $\mathrm{Yb}_{2} \mid \mathrm{r}_{2} \mathrm{O}_{7}$. It should be noted that syntheses of the ruthenium pyrochlores containing La or Ce in the A-site were also attempted in order to evaluate the accuracy of the theoretical phase diagrams, but these pyrochlore phases could not be obtained. This is in agreement with the DFT-calculated phase diagrams (See Figure S7) and, particularly in the case of $\mathrm{Ce}$, can be explained by the rather high total energies (> $150 \mathrm{meV} /$ atom above the convex hull) calculated for the pyrochlore phase (See Table S1). In principle, it may also be possible to produce the La-based ruthenium pyrochlore considering that its total energy is only $19 \mathrm{meV} /$ atom above the convex hull (See Table S1). From the theoretical phase diagram and XRD (See Figure S7), however, we see that there are far too many competing phases and therefore obtaining a phase-pure pyrochlore could prove to be extremely difficult. Furthermore, we recall that the La and Ce-based materials would not be ideal candidates for OER catalysis considering that the pyrochlore phase is not predicted to be stable under OER conditions according to the calculated Pourbaix diagrams (See Figure S6).

Freeze-drying of the spray-freeze precursors yields finely dispersed amorphous precursors which need to be calcined at temperatures above $400{ }^{\circ} \mathrm{C}$ to obtain crystalline phases. ${ }^{41-42}$ The calcination temperature to be used in the pyrochlore syntheses was determined by annealing separate fractions of the sample precursor at progressively higher temperatures until only the single pyrochlore phase was obtained. As an example, the XRD patterns of the $\mathrm{Yb}_{2} \mathrm{Ru}_{2} \mathrm{O}_{7}$ precursor powder annealed at different temperatures are summarized in Figure 2. We find that regardless of the actual chemical composition of the precursor, $\mathrm{RuO}_{2}$ or $\mathrm{IrO}_{2}$ represent the first crystalline phase detected in the diffraction patterns of the annealed precursors once the annealing temperature exceeds $400{ }^{\circ} \mathrm{C}$ (See Figure 2a). The ternary phase apparently conforming to the pyrochlore cubic structure begins to appear in the diffraction patterns at annealing temperatures higher than $600^{\circ} \mathrm{C}$. An increasing of the annealing temperature leads to a decrease of the rutile fraction and a shift of the diffraction maxima positions corresponding to the ternary phase to higher diffraction angles. It needs to be noted that there are no diffraction peaks attributable to ytterbium oxide (e.g. $\mathrm{YbO}$ or $\mathrm{Yb}_{2} \mathrm{O}_{3}$ ) in the observed 
diffraction patterns. The phase-pure ternary phases conforming to a pyrochlore cubic structure require an annealing temperature of at least $1000{ }^{\circ} \mathrm{C}$ regardless of the chemical composition of the system.
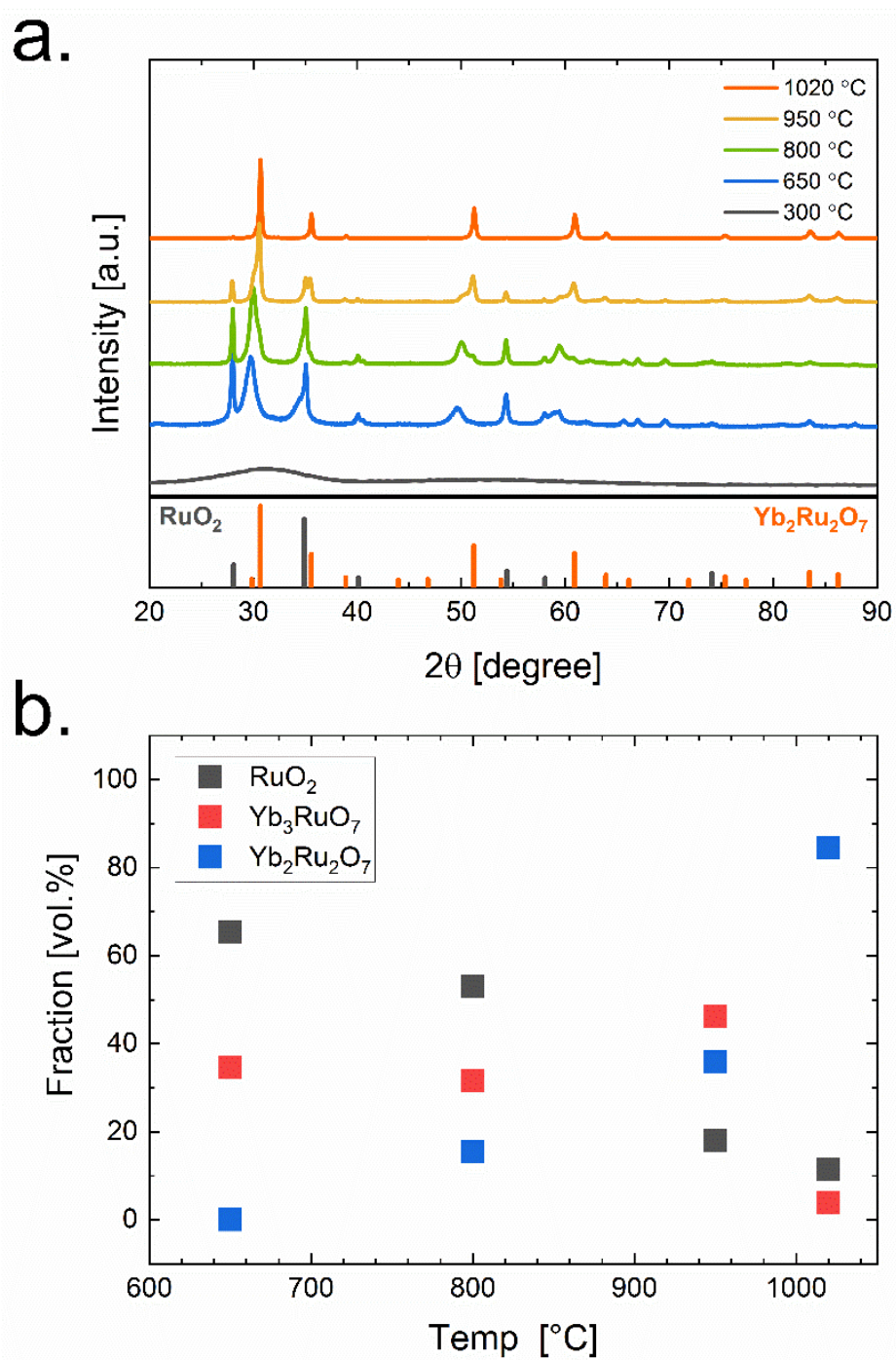

Figure 2. (a) X-ray diffraction patterns of the spray freeze-freeze-dried precursor of the aggregate composition $\mathrm{Yb}_{2} \mathrm{Ru}_{2} \mathrm{O}_{7}$ annealed at different temperatures in air; and (b) phase composition of the spray-freeze freeze-dried precursor corresponding to the aggregate chemical composition $\mathrm{Yb}_{2} \mathrm{Ru}_{2} \mathrm{O}_{7}$ annealed at different temperatures.

The observed behavior reflects the difference in the relative stability of the individual binary and ternary phases one may theoretically conceive. Ruthenium or iridium dioxide represents the first phase that crystallizes from the amorphous precursor at relatively mild temperatures $\left(400\right.$ and $600{ }^{\circ} \mathrm{C}$ for $\mathrm{RuO}_{2}$ and $\mathrm{IrO}_{2}$, respectively). Due to the formation of $\mathrm{RuO}_{2}$ or $\mathrm{IrO}_{2}$, however, the remaining amorphous precursor becomes Ru/Ir deficient with respect to the composition of the ideal pyrochlore 
phase. Hence, the ternary phase structure one observes in materials annealed at temperatures higher than $600{ }^{\circ} \mathrm{C}$ deviates from that of the pyrochlore and instead conforms to a fluorite structure, which is

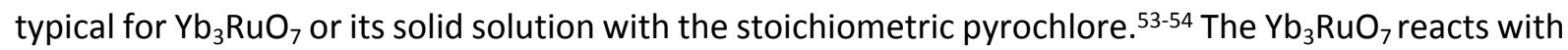
the ruthenium dioxide via solid state reaction at temperatures higher than $800{ }^{\circ} \mathrm{C}$. The temperature dependence of the fractions of all theoretically conceived phases based on full Rietveld refinement of the experimental diffraction patterns is shown in Figure $2 \mathrm{~b}$. An example of the Rietveld analysis plots and the tables containing the refined parameters can be found in the SI (Figure S8 and Table S2). The temperature dependent Rietveld refinement of the phase formation for the ytterbium ruthenium pyrochlore was performed for each temperature after $4 \mathrm{~h}$ of annealing time. After $4 \mathrm{~h}$ at $1020^{\circ} \mathrm{C}$, we still observe around $11 \%$ of $\mathrm{RuO}_{2}$ and $4 \%$ of $\mathrm{Yb}_{3} \mathrm{RuO}_{7}$ remaining in the phase mixture (Figure 2b). After prolonged annealing of up to $24 \mathrm{~h}$ at $1020^{\circ} \mathrm{C}$, however, the target pyrochlore structure was obtained with high phase purity ( $>95 \%)$. Although a complete conversion of the ruthenium dioxide into the pyrochlore requires rather high temperatures and long calcination times, we note that this can be decreased by annealing in a compressed state, e.g. in a pellet. We also note that the presence of additional phases in materials annealed at temperatures lower than $1000{ }^{\circ} \mathrm{C}$ might appear to conflict the theoretical prediction of the thermodynamic stability of the Ru/Ir pyrochlores. Such an interpretation would be, however, misleading and one may assume that the preferential formation of rutile type $\mathrm{RuO}_{2} / \mathrm{IrO}_{2}$ is of kinetic origin and facilitated by a fine dispersion of the precursor since these oxides are stabilized by surface energy. 
a.

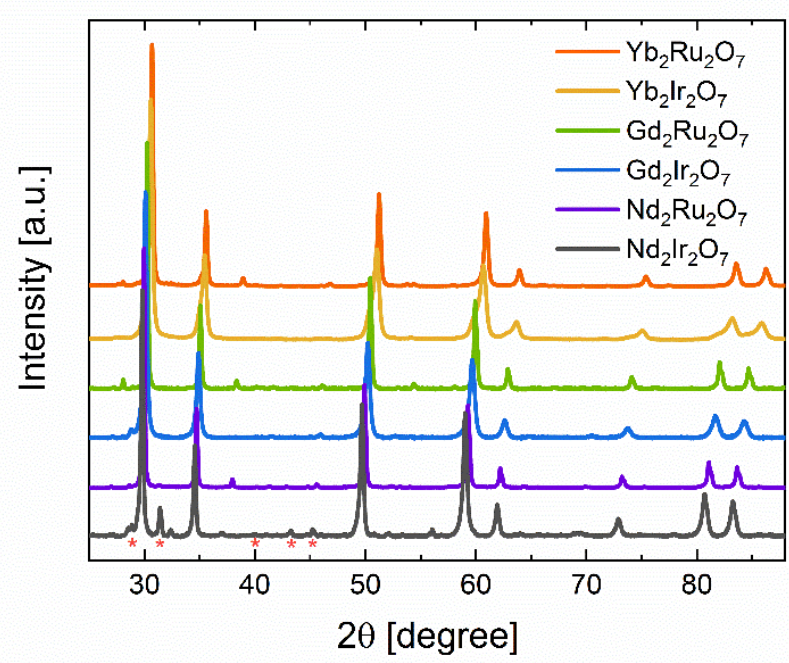

b.

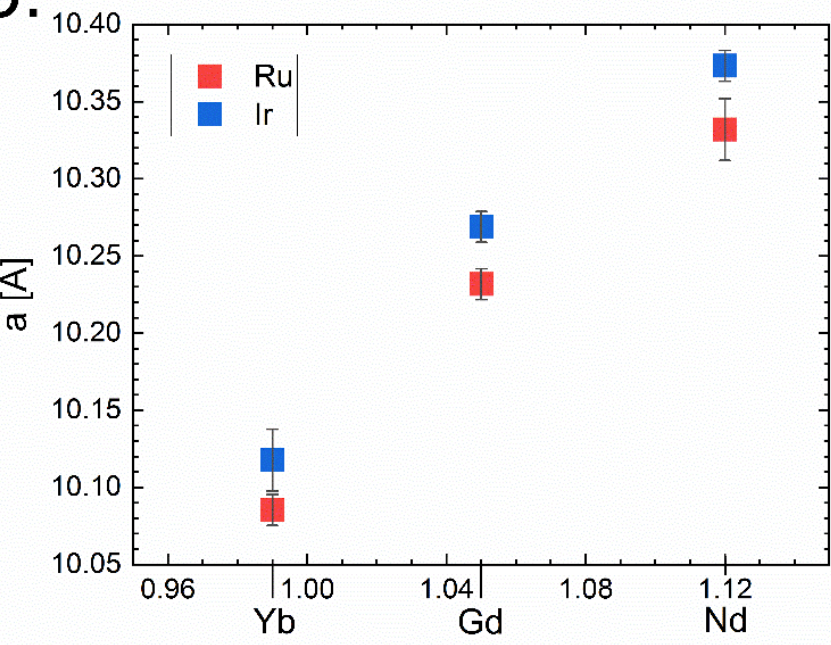

$\mathrm{R}_{\mathrm{A}}[\AA]$

Figure 3. (a) X-ray diffraction patterns of the Ru and Ir-based pyrochlores annealed at $1020{ }^{\circ} \mathrm{C}$ for 4 hours. The formation of $\mathrm{Nd}_{2} \mathrm{Ru}_{2} \mathrm{O}_{7}$ is accompanied by a simultaneous formation of $\mathrm{Nd}_{6} \mathrm{Ir}_{2} \mathrm{O}_{13}$ (orange asterisks); ${ }^{55}$ and (b) unit cell parameters of the Ru and Ir pyrochlores as a function of the rare-earth metal cation.

Regardless of the chemical composition, materials annealed at temperatures higher than $1020^{\circ} \mathrm{C}$ conform to a cubic pyrochlore structural type (space group $\mathrm{Fd} 3 \mathrm{~m}$ ) and their chemical composition conforms to the general formula $\mathrm{A}_{2} \mathrm{~B}_{2} \mathrm{O}_{7}$ (see Figure 3a). The formation of the pyrochlore phase in the target materials is in strong agreement with the predictions based upon the convex hull diagrams (See Figure S4 and Table S1), which predict that the pyrochlore phases of $\mathrm{Gd}_{2} \mathrm{Ru}_{2} \mathrm{O}_{7}, \mathrm{Yb}_{2} \mathrm{Ru}_{2} \mathrm{O}_{7}$, 
It is known that pyrochlore oxides are particularly prone to defects in the A-site and oxygen sites, both of which can ultimately lead to significant alterations in the electronic properties of the material. ${ }^{56}$ Therefore, the actual chemical compositions of the prepared pyrochlore samples were assessed for oxygen vacancies via thermogravimetric reduction (See Figure S9). The experimentally determined oxygen stoichiometry of nearly all pyrochlores was found to be within $0-2 \%$ of the projected oxygen stoichiometry (i.e. $\mathrm{A}_{2} \mathrm{~B}_{2} \mathrm{O}_{7 \pm \delta}$, where $\delta \leq 0.10$ ). Larger deviations were observed in the case of the $\mathrm{Nd}-\mathrm{Ru}$ and $\mathrm{Yb}$-Ru pyrochlores $\left(\mathrm{Nd}_{2} \mathrm{Ru}_{2} \mathrm{O}_{7.21}\right.$ and $\left.\mathrm{Yb}_{2} \mathrm{Ru}_{2} \mathrm{O}_{7.29}\right)$, although higher errors were introduced in these cases due to the low quantities of sample available for analysis and the presence of impurities. In addition to quantifying the oxygen defects, the chemical compositions were evaluated by energy dispersive X-ray spectroscopy (EDX, See Table S3). EDX analysis indicates that the chemical compositions match those projected from the ratios of $\mathrm{Ru} / \mathrm{Ir}$ and lanthanide in the starting solutions. It needs to be stressed that any pronounced A-site deficiency should also result in a change of the electronic state of the catalytically active transition metal cations occupying the B-sites of the pyrochlore structure (i.e. Ru/Ir). Such a change in the electronic state would therefore be reflected in the Ru K and Ir $L_{\text {III }} \mathrm{X}$-ray absorption spectra, specifically in the position of the absorption edge (See Figure S10). According to the X-ray absorption spectra of prepared pyrochlore materials, we observe absorption edge positions of $22130 \mathrm{eV}$ and $11217 \mathrm{eV}$ for the Ru K edge and Ir LIII edge spectra, respectively. Considering that these edge positions are in strong agreement with those reported for $\mathrm{RuO}_{2}{ }^{19,57}$ and $\mathrm{IrO}_{2}{ }^{9,14}$ in which the oxidation state of transition metal cation is IV, this apparently does not support the possibility an A-site deficiency.

The corresponding unit cell parameters of the synthesized materials are shown in Figure $3 \mathrm{~b}$. The unit cell parameter clearly tracks the ionic radius of the cation residing in the A site (i.e. the rare- 
earth metal). This agrees well with the results of Kennedy at al. ${ }^{58}$, who showed that there is a linear dependence between the unit cell parameter and the ionic radii of the A-site cation within the lanthanide ruthenate and iridate series.

As expected from the high annealing temperatures, the resulting pyrochlore catalysts lose much of their nanosize character yielding particle sizes ranging from the nano to the micron scale (See Figure 4). The smallest average particle size of ca. $80 \mathrm{~nm}$ is found for $\mathrm{Yb}_{2} \mathrm{Ru}_{2} \mathrm{O}_{7}$ and $\mathrm{Gd}_{2} \mathrm{Ru}_{2} \mathrm{O}_{7}$ while $\mathrm{Yb}_{2} \mid \mathrm{Ir}_{2} \mathrm{O}_{7}$ and $\mathrm{Gd}_{2} \mid \mathrm{r}_{2} \mathrm{O}_{7}$ are in the range of 150-200 nm. Much larger particles in the average range of $450 \mathrm{~nm}$ are observed for the neodymium-based samples.
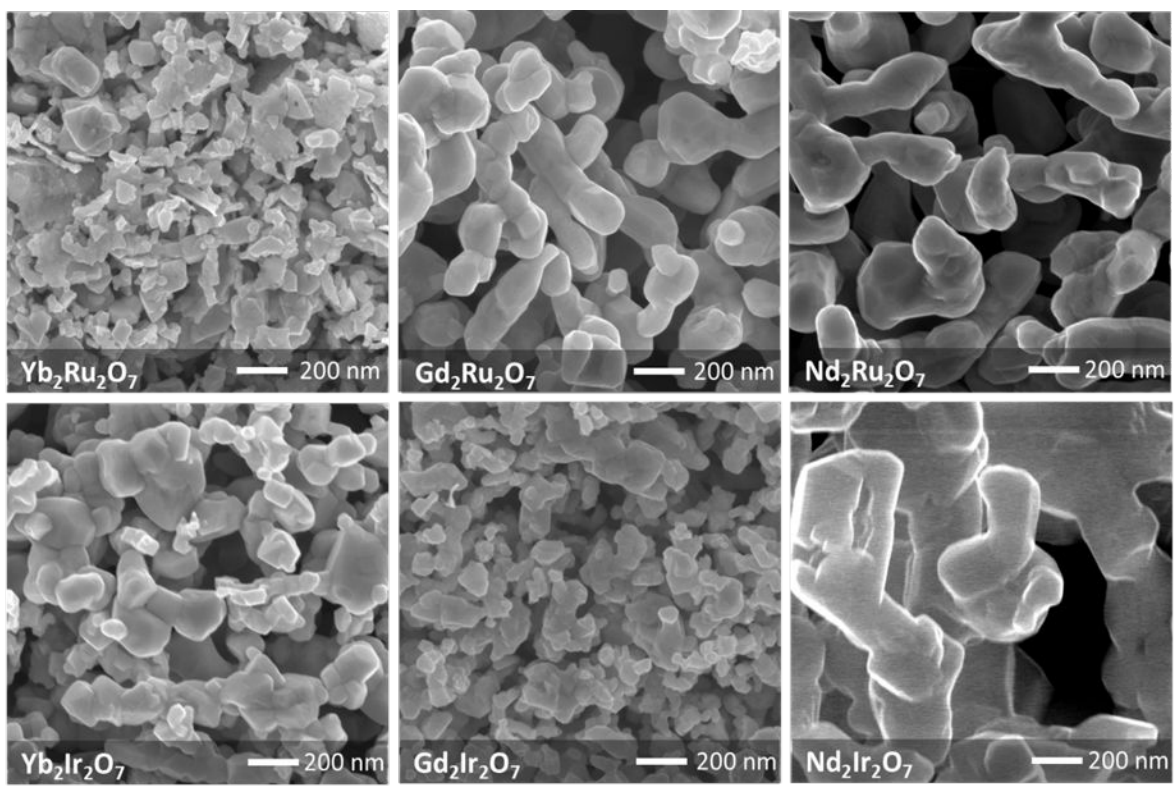

\begin{tabular}{|l|l|}
\hline Sample & $\begin{array}{l}\text { Diameter } \\
\text { [nm] }\end{array}$ \\
\hline $\mathrm{Yb}_{2} \mathrm{Ru}_{2} \mathrm{O}_{7}$ & $83 \pm 11$ \\
\hline $\mathrm{Gd}_{2} \mathrm{Ru}_{2} \mathrm{O}_{7}$ & $173 \pm 12$ \\
\hline $\mathrm{Nd}_{2} \mathrm{Ru}_{2} \mathrm{O}_{7}$ & $350 \pm 12$ \\
\hline $\mathrm{Yb}_{2} \mathrm{Ir}_{2} \mathrm{O}_{7}$ & $156 \pm 9$ \\
\hline $\mathrm{Gd}_{2} \mathrm{Ir}_{2} \mathrm{O}_{7}$ & $142 \pm 5$ \\
\hline $\mathrm{Nd}_{2} \mathrm{Ir}_{2} \mathrm{O}_{7}$ & $348 \pm 23$ \\
\hline
\end{tabular}

statistical analysis of size distribution from 400 to 1000 particles.

Figure 4. SEM micrographs depicting the morphologies of the Ru and Ir-based pyrochlores prepared by the spray-freeze freeze-drying approach with subsequent annealing at $1020^{\circ} \mathrm{C}$ for 4 hours.

\section{Electrochemical Measurements}

Presented in Figure 5a are the Tafel plots produced from steady-state chronoamperometric measurements for the prepared pyrochlore catalysts, which show that all materials are electrochemically active for the OER in acidic media. Upon further inspection, it is evident that nearly all materials display a similar Tafel slope within the range of ca. $57-64 \mathrm{mV} \mathrm{dec}{ }^{-1}$ regardless of the chemical composition. The close similarity in the observed Tafel slopes indicates that the OER mechanism is identical on all pyrochlore-based catalysts and that the entire process is most likely controlled by a chemical step following the first electron transfer. ${ }^{59}$ In contrast, $\mathrm{Gd}_{2} \mathrm{Ir}_{2} \mathrm{O}_{7}$ displays a slightly lower slope of ca. $46 \mathrm{mV} \mathrm{dec}-1$, which is similar to that of $\mathrm{IrO}_{2}$ and indicates that the OER may be limited by the second electron transfer step. Tafel slopes within the range of $45-55 \mathrm{mV} \mathrm{dec} \mathrm{c}^{-1}$ are 
a.

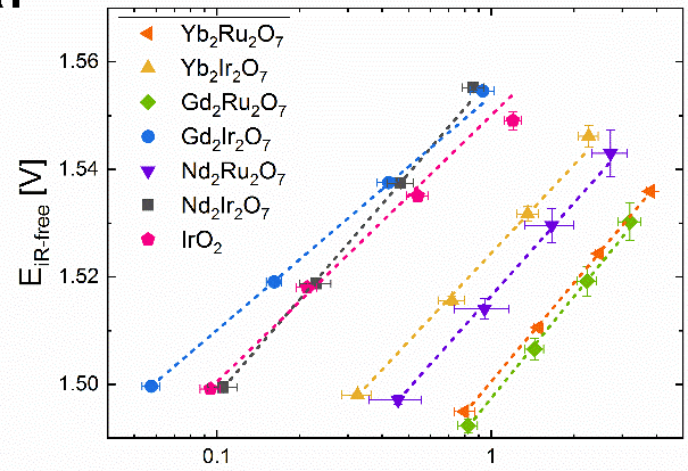

C.

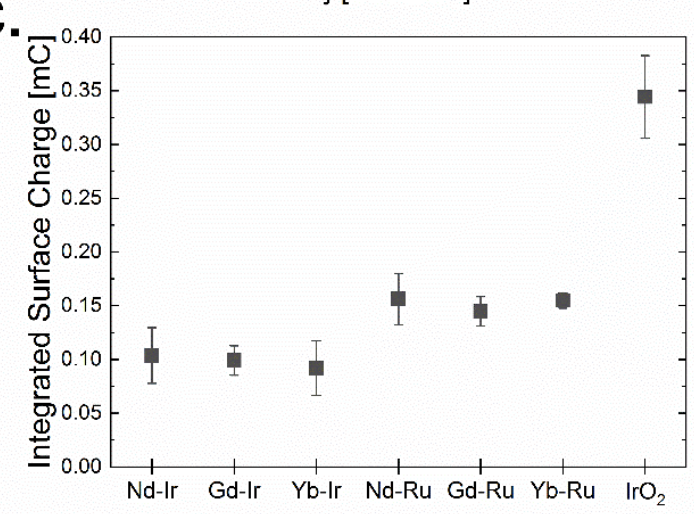

b.

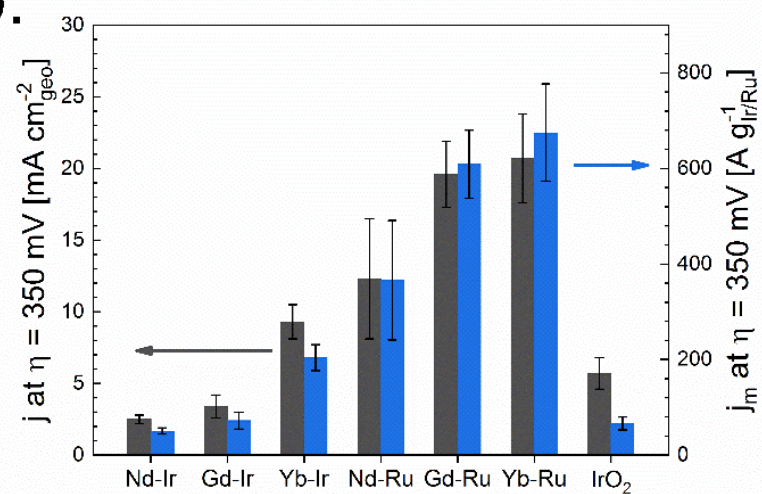

d.

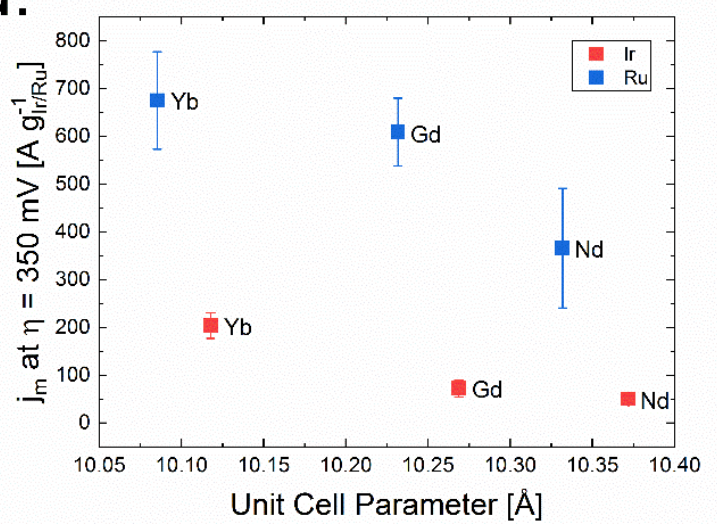

Figure 5. (a) Tafel plots of the oxygen evolution on nanoparticulate Ru and Ir-based pyrochlore catalysts extracted from steady-state chronoamperometric measurements in $0.1 \mathrm{M} \mathrm{HClO}_{4}$, (b) measured OER activities for the prepared pyrochlore series, (c) surface charge of the pyrochlore samples as calculated from cyclic voltammograms (average integration of anodic and cathodic scans) measured between 1.0 and 1.4 V vs. RHE (Note: CVs were recorded before and after the steady-state polarization measurements shown in panel (a)), and (d) the average specific activity of the Ru and Ir pyrochlores as a function of the unit cell parameter. Activity data for $\mathrm{IrO}_{2}$ was previously reported in references ${ }^{9,14}$.

The geometric area-based and precious metal mass-based OER activities of each catalyst are compared in Figure $5 \mathrm{~b}$. We note that all pyrochlore materials display a comparable surface charge as estimated from the integration of cyclic voltammograms recorded between 1.0 and $1.4 \mathrm{~V}$ (See Figure 5c). Given that all of the pyrochlore materials are morphologically and structurally similar, this 
indicates that all materials have roughly the same ECSA. While the Ru and Ir-based pyrochlore series show comparable integrated charge values, we observe that the $\mathrm{IrO}_{2}$ benchmark sample has an integrated surface charge that is roughly 2-4 times larger, which suggests that the ECSA of the $\mathrm{IrO}_{2}$ sample is much greater than that of the pyrochlores. Despite these differences, we clearly observe that all Ru-based pyrochlores display superior OER activity as compared to the benchmark $1 \mathrm{rO}_{2}$ catalyst. At first glance, it appears that only $\mathrm{Yb}_{2} \mid \mathrm{Ir}_{2} \mathrm{O}_{7}$ from the Ir-based series outperforms the benchmark $1 \mathrm{IO}_{2}$ catalyst. When the precious metal mass-based activities are compared, however, we see that $\mathrm{Nd}_{2} \mid \mathrm{r}_{2} \mathrm{O}_{7}$ and $\mathrm{Gd}_{2} \mathrm{Ir}_{2} \mathrm{O}_{7}$ also show comparable activities to $\mathrm{IrO}_{2}$ even though they have considerably lower ECSAs. More importantly, it is interesting to note that the OER activity (e.g. current density compared at $\eta=$ $350 \mathrm{mV}$ ) decreases with the expansion of the unit cell parameter (see Figure $5 \mathrm{~d}$ ). The OER activity of pyrochlores has been previously assigned to the cations residing in the B-site, specifically to the bonding strength between the B-site cation and oxygen. ${ }^{15}$ The observed trends can be related to center of the $d$ band formed by the $d$ orbitals of the cation residing in B-site. The OER activity trends outlined in the present study can be rationalized in a similar manner. As follows from the diffraction results, the size of the cation in A-site controls the spacing of the cations in the whole structure and consequently changes the position of the $d$ band center. The observed trend shows that the final electrocatalytic activity cannot be related to a single pyrochlore's component but rather reflects the behavior of the whole structure.

In addition to evaluating the OER activity of each material, the short-term electrochemical stability of each pyrochlore was investigated by applying a simple protocol in which the electrocatalyst was subjected to a series of brief potential-steps between 1.0 and $1.6 \mathrm{~V}$ vs. RHE (i.e. a potential close to the open circuit potential (OCP) and a potential where there is a significant OER current, respectively). Shown in Figure 6a are the normalized OER currents for each material, which were recorded at $1.6 \mathrm{~V}$ (i.e. the normalized OER activity at $1.6 \mathrm{~V}$ ) after every 25 potential-step cycles. While it can be seen that $\mathrm{IrO}_{2}$ loses roughly $30 \%$ of its initial activity, we observe that on average the pyrochlores lose only about $10-17 \%$ of their initial OER activity over the full course of the 500 potentialstep cycles, indicating that all pyrochlore materials display a higher stability than that of the benchmark catalyst. We note, however, that there exists a significant difference in the behavior of the pyrochlores featuring $\mathrm{Yb}$ and $\mathrm{Gd}$ versus those containing $\mathrm{Nd}$. While the $\mathrm{Yb}$ and $\mathrm{Gd}$ pyrochlores show a gradual decay of the OER activity with cycling, the pyrochlores containing $\mathrm{Nd}$ display a gradual increase in the OER activity with cycling. We observe that the OER activity increase either reaches a maximum before gradually decreasing (i.e. as in the case of $\mathrm{Nd}_{2} \mathrm{Ru}_{2} \mathrm{O}_{7}$ ) or continues to increase with repetitive cycling (i.e. as for $\mathrm{Nd}_{2} \mid \mathrm{r}_{2} \mathrm{O}_{7}$ ). The concomitant observation of the increasing double layer charge (see Figure $6 b)$ for all materials clearly proves that the ECSA of the pyrochlores increases regardless of the chemical 

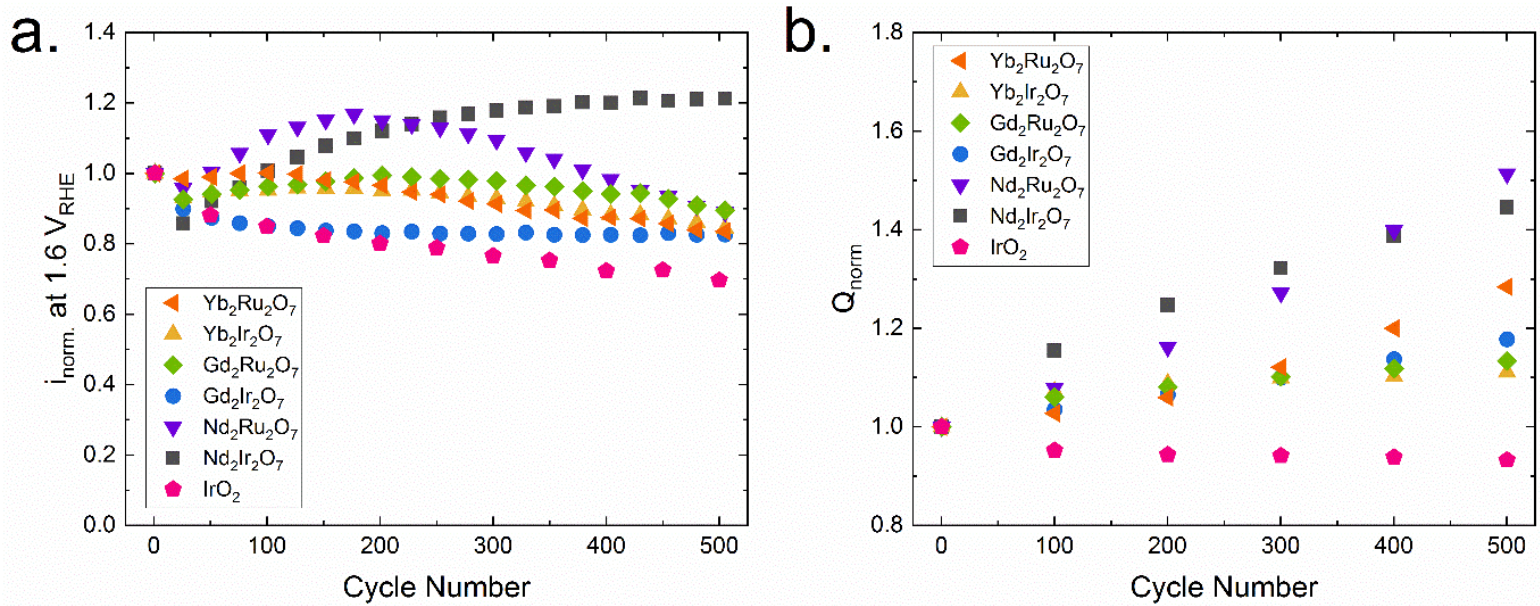

Figure 6. Electrochemical stability measurements for the pyrochlore samples showing the normalized current density at $1.6 \mathrm{~V}_{\mathrm{RHE}}(\mathrm{a})$ and the normalized surface charge calculated from cyclic voltammograms recorded after every 100 potential-step cycles (b) as a function of potential-step cycle number. Stability data for $\mathrm{IrO}_{2}$ was previously reported in references ${ }^{9,14}$.

ICP-OES analysis of the electrolyte solutions collected at the end of the stability measurements undoubtedly confirms that some dissolution of the pyrochlore phase is occurring (see Table 1). Specifically, A-site cation leaching is shown to occur for all materials, while dissolution of the B-site occurs primarily for materials containing $\mathrm{Ru}$ and/or $\mathrm{Nd}$. If one refers to the calculated Pourbaix diagrams (see Figure 7) and considers the theoretically predicted stability range for each material, then it is not too surprising that some preferential dissolution occurs. In fact, the combined results of the stability measurements and ICP-OES analysis corroborate the predicted phase stability quite well. This is most obvious for the $\mathrm{Nd}_{2} \mathrm{Ir}_{2} \mathrm{O}_{7}$ and $\mathrm{Nd}_{2} \mathrm{Ru}_{2} \mathrm{O}_{7}$ pyrochlore materials, for which the pyrochlore phases are not predicted to be stable under OER operating conditions. It needs to be noted, however, that the model used to construct the surface Pourbaix diagrams does not include surface effects, such as reconstruction, passivation, coverages, etc. Therefore, we observe that the separation of $\mathrm{Nd}$ and Ir/Rubased phases is predicted to be a thermodynamically spontaneous process under OER conditions. In 
this case, we should expect a large surface area $\mathrm{IrO}_{2} / \mathrm{RuO}_{2}$ to form under operating conditions as $\mathrm{Nd}$ is dissolved, similar to that reported previously. ${ }^{14,62}$ Furthermore, we would expect any $\mathrm{RuO}_{2}$ to be eventually oxidized to $\mathrm{RuO}_{4}^{-}$and subsequently dissolved, ultimately leading to the complete disintegration of the pyrochlore structure. This behavior is reflected rather well in the Figure 6a by the rapid loss of OER activity after ca. 175 cycles for $\mathrm{Nd}_{2} \mathrm{Ru}_{2} \mathrm{O}_{7}$, whereas the activity continues to increase for $\mathrm{Nd}_{2} \mathrm{Ir}_{2} \mathrm{O}_{7}$ as $\mathrm{Nd}$ is leached and $\mathrm{IrO}_{2}$ is left behind. It needs to be noted that ICP does not distinguish between chemical corrosion (i.e. leaching of the catalyst's components into solution) from particles that can be mechanically disintegrated from the electrode. Keeping this in mind, one should also avoid speculative conclusions on the nature of the observed stability trends since the tested pyrochlores featured significantly bigger particle sizes. It needs to be stressed, however, that this does not demote the importance and relevance of the presented stability or activity data from assessment of practical implementation of the catalyst in an electrolyzer-like environment.

Table 1. Results of the ICP-OES analyses of electrolyte solutions collected from the electrochemical stability measurements of the pyrochlore samples. Species that are below the detection limit (DL) indicated by $(<)$. Reported values are estimated to have an error of $+/-10 \%$. The $A: B$ ratio indicates the amount of dissolved A-site cations as compared to the amount of dissolved B-site cations.

\begin{tabular}{|c|c|c|c|c|c|c|}
\hline Pyrochlore & $\begin{array}{c}\mathrm{Nd}, \\
\mathrm{ng} / \mathrm{ml}\end{array}$ & $\begin{array}{c}\text { Gd, } \\
\mathrm{ng} / \mathrm{ml}\end{array}$ & $\begin{array}{c}\mathrm{Yb}, \\
\mathrm{ng} / \mathrm{ml}\end{array}$ & $\begin{array}{c}\text { Ir, } \\
\mathrm{ng} / \mathrm{ml}\end{array}$ & $\begin{array}{c}\mathrm{Ru}, \\
\mathrm{ng} / \mathrm{ml}\end{array}$ & $A: B$ \\
\hline $\mathrm{Nd}_{2} \mathrm{Ir}_{2} \mathrm{O}_{7}$ & 29.4 & & & 11 & & 2.7 \\
\hline $\mathrm{Gd}_{2} \mathrm{Ir}_{2} \mathrm{O}_{7}$ & & 4.0 & & $<$ & & $>4$ \\
\hline $\mathrm{Yb}_{2} \mathrm{Ir}_{2} \mathrm{O}_{7}$ & & & 7.23 & $<$ & & $>7$ \\
\hline $\mathrm{Nd}_{2} \mathrm{Ru}_{2} \mathrm{O}_{7}$ & 45.8 & & & & 14.6 & 3.1 \\
\hline $\mathrm{Gd}_{2} \mathrm{Ru}_{2} \mathrm{O}_{7}$ & & 10.5 & & & 3.0 & 3.5 \\
\hline $\mathrm{Yb}_{2} \mathrm{Ru}_{2} \mathrm{O}_{7}$ & & & 7.13 & & 2.0 & 3.6 \\
\hline $\mathrm{DL}$ & 0.4 & 0.2 & 0.03 & 1 & 0.7 & - \\
\hline
\end{tabular}

$\mathrm{Gd}_{2} \mathrm{Ir}_{2} \mathrm{O}_{7}$ and $\mathrm{Yb}_{2} \mid \mathrm{r}_{2} \mathrm{O}_{7}$, on the other hand, have the largest $\mathrm{pH}$-potential range in which the pyrochlore phases are predicted to be stable. Accordingly, we observe that these materials show virtually no Ir dissolution and minimal dissolution of the A-site (see Table 1). In contrast, $\mathrm{Gd}_{2} \mathrm{Ru}_{2} \mathrm{O}_{7}$ and $\mathrm{Yb}_{2} \mathrm{Ru}_{2} \mathrm{O}_{7}$ are predicted to undergo some degree of phase separation and this is confirmed by higher concentrations of dissolved Ru in conjunction with the dissolved A-site cation. Overall, the actual OER activity losses observed for all listed catalysts are rather small. The gradual OER activity losses are in 
part due to dissolution of the material, but may also be due to a surface reconstruction in which the surface becomes enriched with the catalytically inactive A-site cation. Viability of such a mechanism, however, needs to be further confirmed. Steric reasons can be used to justify the heightened stability of the $\mathrm{Gd}$ and $\mathrm{Yb}$-based pyrochlores as compared to the $\mathrm{Nd}$-pyrochlores considering that the ionic radius of $\mathrm{Gd}$ or $\mathrm{Yb}$ along with those of $\mathrm{Ru}$ or $\mathrm{Ir}$ match well with the required radius of the $\mathrm{A} / \mathrm{B}$ site cations to enable formation of pyrochlores. ${ }^{63}$ Ultimately, we can attribute the poor phase stability of the $\mathrm{Nd}$ containing pyrochlores to the structural strain arising from the rather bulky neodymium residing within the pyrochlore structure.
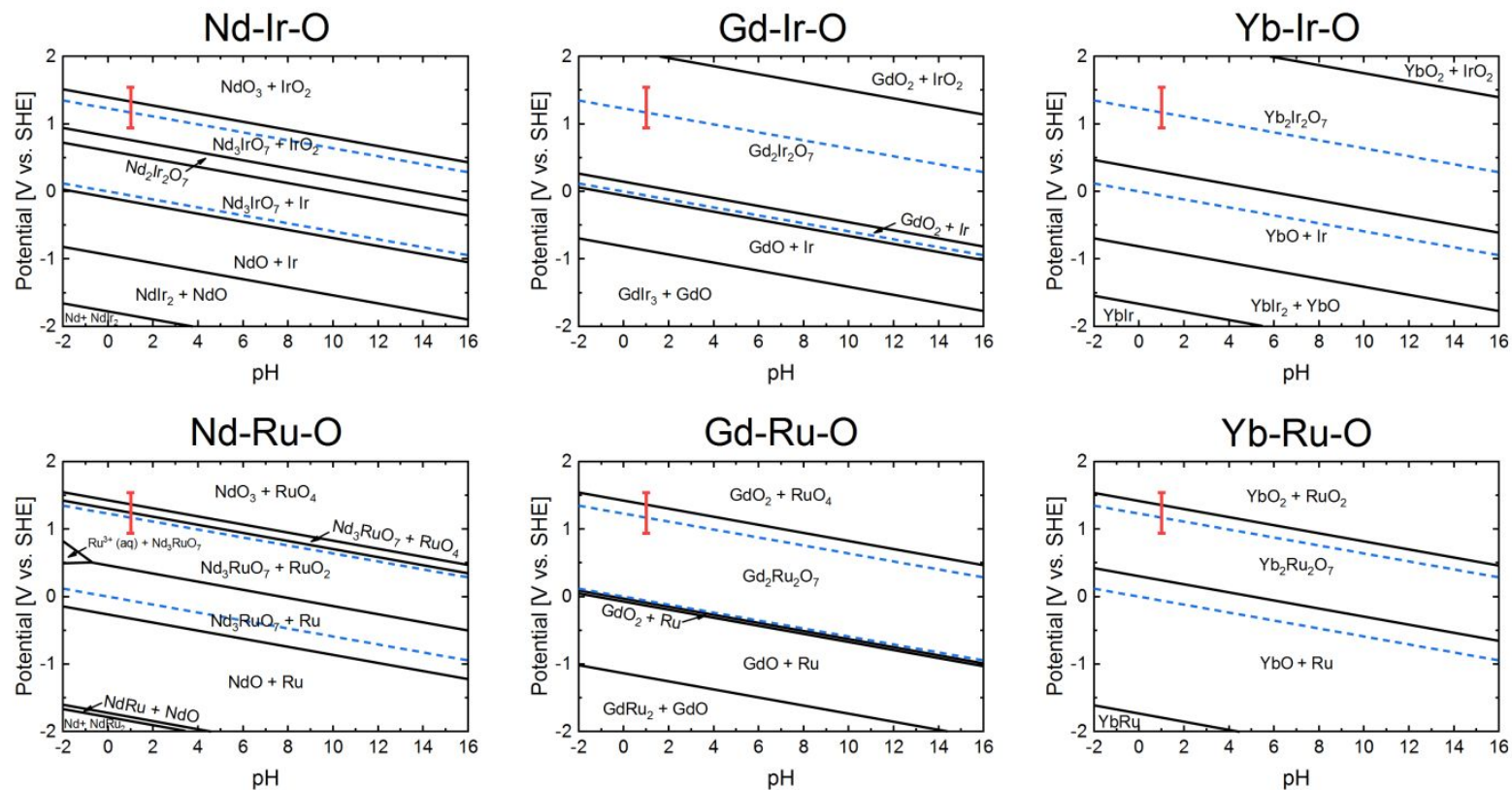

Figure 7. DFT-calculated Pourbaix diagrams for synthesized rare-earth pyrochlore series. The dotted blue lines indicate the thermodynamic redox potentials within which water is stable. The red bar at $\mathrm{pH}$ $=1$ indicates the operating potential range examined in this study (i.e. 1.0 to $1.6 \mathrm{~V}$ vs. RHE).

\section{Differential electrochemical mass spectrometry}

Since the decrease in the specific activity observed in the potential-step stability measurements suggests possible selective dissolution of the B-site cation, one needs to assess the actual mechanism of the oxygen evolution on pyrochlore electrodes. Although it is difficult to distinguish conclusively between both possible mechanisms of the pyrochlore activity decrease, the tendency towards the active component dissolution is often associated with a significant contribution from the lattice oxygen evolution reaction (LOER) mechanism towards the overall oxygen evolution process. ${ }^{64-65}$ A contribution from the LOER-like mechanism is typical for both $\mathrm{RuO}_{2}$ and $\mathrm{IrO}_{2}$ and can be 
detected by following the isotopic distribution of the evolved oxygen in ${ }^{18} \mathrm{O}$ labeled water. ${ }^{66-68}$ The results of the DEMS experiments of the OER on pyrochlores (evaluated for only for those which showed the highest $\mathrm{OER}$ activity, i.e. $\mathrm{Yb}_{2} \mathrm{Ru}_{2} \mathrm{O}_{7}$ and $\left.\mathrm{Gd}_{2} \mathrm{Ru}_{2} \mathrm{O}_{7}\right)$, are summarized in Figure 8. Keeping in mind the natural distribution of the oxygen isotopes, one may assume that the surface of the pyrochlore is composed solely of ${ }^{16} \mathrm{O}$. Oxygen evolution in ${ }^{18} \mathrm{O}$ labelled water (on an ${ }^{16} \mathrm{O}$ enriched surface) may in principle produce molecular oxygen of different isotopic compositions: ${ }^{18} \mathrm{O}_{2}$ with molecular mass of 36 , ${ }^{16} \mathrm{O}^{18} \mathrm{O}$ with molecular mass of 34 , and ${ }^{16} \mathrm{O}_{2}$ with molecular mass of 32 . It needs to be noted that, with respect to the composition of the electrolyte solution, significant production of the ${ }^{16} \mathrm{O}^{18} \mathrm{O}$ or ${ }^{16} \mathrm{O}_{2}$ is not possible without involvement of the pyrochlore lattice (LOER mechanism) which should increase the probability of the active component ( $\mathrm{Ru} / \mathrm{Ir})$ dissolution. As shown in Figure 8, we were able to detect two types of produced molecular oxygen: one characterized by the molecular ion with $\mathrm{m} / \mathrm{z}$ of $36\left({ }^{18} \mathrm{O}_{2}\right)$ and the other with $\mathrm{m} / \mathrm{z}$ of $34\left({ }^{16} \mathrm{O}^{18} \mathrm{O}\right)$. The fraction of produced oxygen that can be attributed to ${ }^{16} \mathrm{O}^{18} \mathrm{O}(\mathrm{m} / \mathrm{z}=34)$ amounts to only ca. 0.04 (See Figure 9). We observe that the amount of ${ }^{16} \mathrm{O}^{18} \mathrm{O}$ produced is time invariant and can, therefore, be attributed to the residual fraction of $\mathrm{H}_{2}{ }^{16} \mathrm{O}$. This type of behavior is not compatible with the LOER mechanism, which is minimal in comparison to previous reports detailing the LOER on $\mathrm{RuO}_{2}$ or $\mathrm{IrO}_{2}{ }^{66-68}$ It should be mentioned, however, that a more recent study also detected no involvement of the LOER on highly crystalline $\mathrm{RuO}_{2}$ films. ${ }^{51}$ The authors suggest that LOER is involved only in amorphous $\mathrm{RuO}_{2}$ or low-coordinated nanoparticle surfaces with large surface-to-bulk ratios. Recent reports have also suggested that high amounts of oxygen vacancies may be crucial for LOER to occur. ${ }^{65,69-70}$ The decrease in the specific activity we observe during repetitive oxygen evolution cycling can, therefore, be primarily ascribed to collapse of the surface structure following the dissolution of the rare-earth metals. This conclusion is further supported by the fact that we detect far greater concentrations of the rare-earth element as compared to the active element via ICP-OES in the electrolyte solutions collected after the RDE stability measurements (See Table 1). 

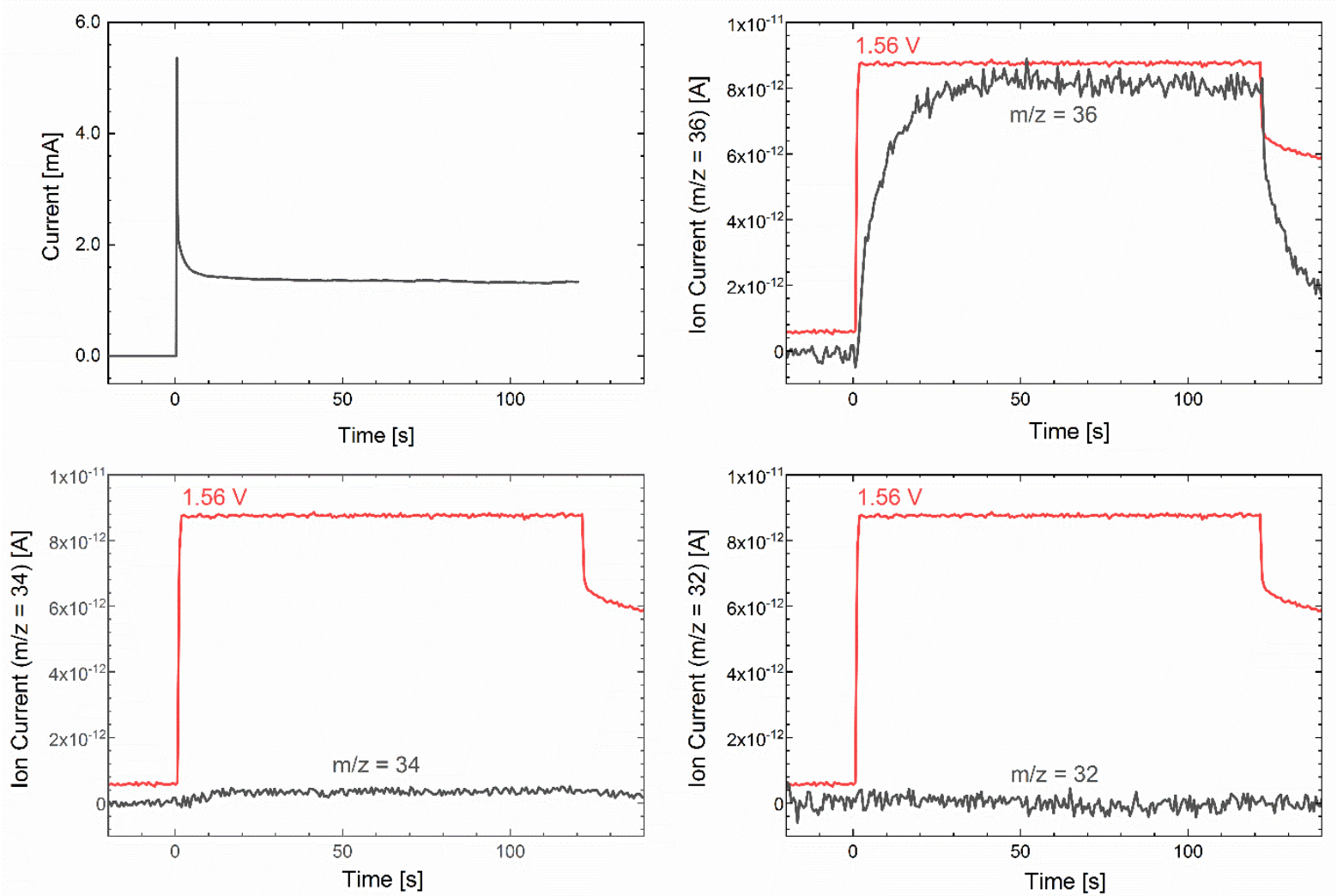

Figure 8. Electrochemical current and DEMS signal (ion current) evolved on $\mathrm{Gd}_{2} \mathrm{Ru}_{2} \mathrm{O}_{7}$ for mass fragments $\mathrm{m} / \mathrm{z}$ corresponding to oxygen of different isotope composition: $36\left({ }^{18} \mathrm{O}_{2}\right), 34\left({ }^{18} \mathrm{O}^{16} \mathrm{O}\right)$, and 32 $\left({ }^{16} \mathrm{O}_{2}\right)$. The recorded potential step signal is shown in red $(1.56 \mathrm{~V})$.
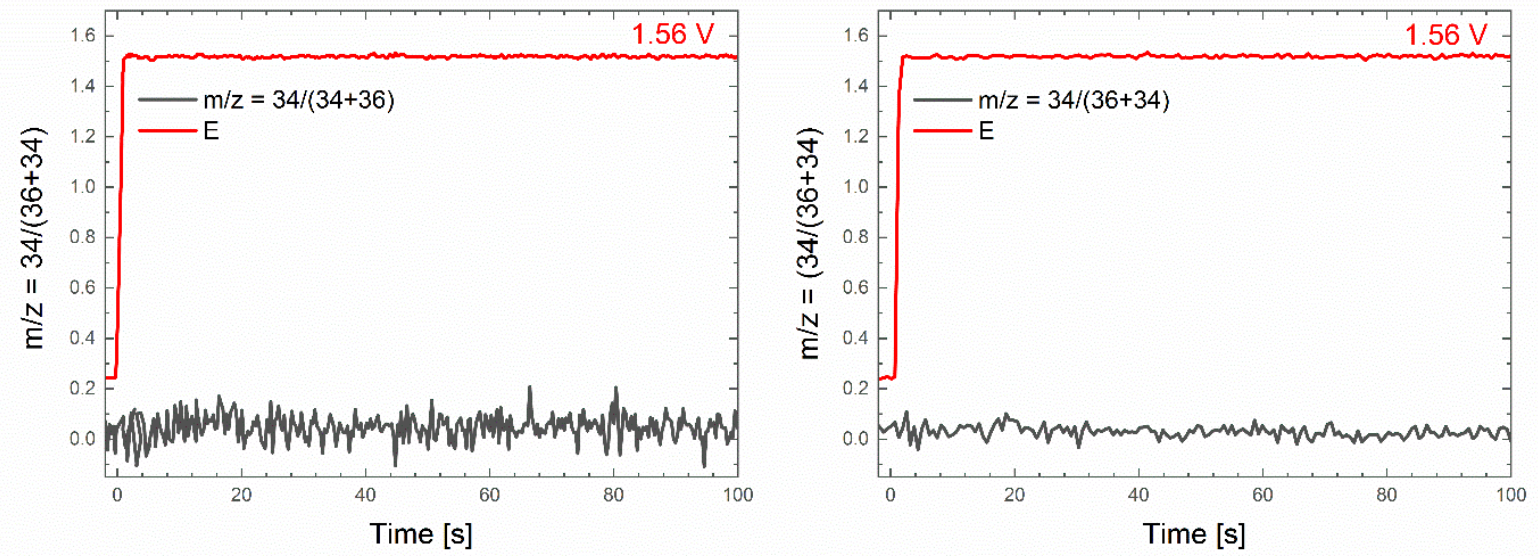

Figure 9. Fraction of $\mathrm{m} / \mathrm{z} 34$ produced during potential step experiment with ${ }^{18}$ O-labeled $0.1 \mathrm{M} \mathrm{HClO}_{4}$ at a potential of $1.56 \mathrm{~V}$ vs. $\mathrm{RHE}$ on $\mathrm{Yb}_{2} \mathrm{Ru}_{2} \mathrm{O}_{7}$ (left) and $\mathrm{Gd}_{2} \mathrm{Ru}_{2} \mathrm{O}_{7}$ (right).

\section{Conclusions}

Density functional theory calculations were employed in a targeted screening approach for identifying potentially suitable OER electrocatalysts based on rare-earth ruthenate/iridate pyrochlore 
oxides. From the many materials screened, those containing $\mathrm{Nd}, \mathrm{Gd}$, or $\mathrm{Yb}$ in A site and Ru or Ir in the B site position were identified as promising OER candidates due to their theoretically predicted phase stability and conductivity. In agreement with the theoretical phase diagrams, the pyrochlore phase of each target material was successfully obtained via the spray-freeze freeze-dry synthesis approach. Xray diffraction of the produced material powders reveals that the lattice parameter of the pyrochlore structure increases with the increasing radius of the lanthanide metal cation, indicating that the structure is primarily controlled by the size of the A-site cation.

All materials were evaluated for their OER activity and stability in acid media. While $\mathrm{Gd}_{2} \mathrm{Ir}_{2} \mathrm{O}_{7}$ and $\mathrm{Nd}_{2} \mathrm{Ir}_{2} \mathrm{O}_{7}$ display comparable mass activities to the $1 \mathrm{IO}_{2}$ benchmark catalyst, $\mathrm{Yb}_{2} \mid \mathrm{Ir}_{2} \mathrm{O}_{7}$ and the ruthenate series $\left(\mathrm{Nd}_{2} \mathrm{Ru}_{2} \mathrm{O}_{7}, \mathrm{Gd}_{2} \mathrm{Ru}_{2} \mathrm{O}_{7}\right.$, and $\left.\mathrm{Nd}_{2} \mathrm{Ru}_{2} \mathrm{O}_{7}\right)$ displayed considerably higher activities despite having significantly lower ECSAs as approximated from the integration of the surface charge capacitance. We note that the activity of the pyrochlores seems to track the size of the ion in the Asite such that the OER activity generally increases with decreasing radius of the rare-earth element, which implies that control of the local structure can have a significant impact on the electrocatalytic properties of the pyrochlore.

All materials demonstrated a higher stability than the $\mathrm{IrO}_{2}$ benchmark catalyst. The calculated Pourbaix diagrams in conjunction with ICP-OES explains the differences in stability of the pyrochlore phases by preferential dissolution of rare-earth element. In the case of the Ru-based pyrochlore series, a simultaneous dissolution of the active element takes place. DEMS analysis further reveals that there is no involvement of the LOER and therefore that the primary loss of activity can be attributed to a collapse of the surface structure resulting from rare-earth metal dissolution. The experimental results presented herein are in strong agreement with the theoretical predictions and underscore the viability of computational screening of promising OER candidate catalyst materials based on conductivity, phase stability, and pH-dependent electrochemical stability.

\section{Supporting Information}

Example of cycling voltammograms (Figure S1). Calculated band energy diagrams, PDOS diagrams, phase diagrams, Pourbaix diagrams, and XRD analysis (Figures S2-S7) and the calculated total energies (Table S1) for synthesized and predicted pyrochlore materials. XRD patterns and Rietveld analysis (Figure S8 and Table S2). Compositional EDX data (Table S3), TGA analysis (Figure S9), and XANES spectra (Figure S10) of synthesized pyrochlore materials.

\section{Acknowledgements}


D.F.A., E.F., and T.J.S. gratefully acknowledge and thank InnoSuisse and the Swiss Competence Center for Energy Research (SCCER) Heat \& Electricity Storage for their financial support. R.P. gratefully acknowledges the support of the European Commission within the framework of the Innovative Training Network Elcorel (Contract 722614). We would also like to thank Silvia Köchli and Laboratory of Environmental Chemistry (PSI) for the measurement of samples via ICP-OES. PSI is acknowledged for the provision of beam time at the SuperXAS beamline of the Swiss Light Source SLS.

\section{References}

(1) Bertuccioli, L.; Chan, A.; Hart, D.; Lehner, F.; Madden, B.; Standen, E. Development of Water Electrolysis in the European Union; Fuel Cells and Hydrogen Joint Undertaking: 2014; p 83.

(2) Schmidt, O.; Gambhir, A.; Staffell, I.; Hawkes, A.; Nelson, J.; Few, S. Future Cost and Performance of Water Electrolysis: An Expert Elicitation Study. Int. J. Hydrogen Energy 2017, 42 (52), 30470-30492.

(3) Schiebahn, S.; Grube, T.; Robinius, M.; Tietze, V.; Kumar, B.; Stolten, D. Power to Gas: Technological Overview, Systems Analysis and Economic Assessment for a Case Study in Germany. Int. J. Hydrogen Energy 2015, 40 (12), 4285-4294.

(4) Buttler, A.; Spliethoff, H. Current Status of Water Electrolysis for Energy Storage, Grid Balancing and Sector Coupling Via Power-to-Gas and Power-to-Liquids: A Review. Renewable and Sustainable Energy Reviews 2018, 82, 2440-2454.

(5) Carmo, M.; Fritz, D. L.; Mergel, J.; Stolten, D. A Comprehensive Review on PEM Water Electrolysis. Int. J. Hydrogen Energy 2013, 38 (12), 4901-4934.

(6) Green Light for Green Hydrogen at Energiepark Mainz. Theurer, M., Ed. Stadtwerke Mainz AG: Mainz, Germany, 2015.

(7) Proton Onsite MW Electrolyser Passes Half-Million Cell Hours. Fuel Cells Bulletin 2016, 2016 (2), 8.

(8) Babic, U.; Suermann, M.; Büchi, F. N.; Gubler, L.; Schmidt, T. J. Critical Review-Identifying Critical Gaps for Polymer Electrolyte Water Electrolysis Development. J. Electrochem. Soc. 2017, 164 (4), F387F399.

(9) Abbott, D. F.; Lebedev, D.; Waltar, K.; Povia, M.; Nachtegaal, M.; Fabbri, E.; Copéret, C.; Schmidt, T. J. Iridium Oxide for the Oxygen Evolution Reaction: Correlation between Particle Size, Morphology, and the Surface Hydroxo Layer from Operando XAS. Chem. Mater. 2016, 28 (18), 6591-6604.

(10) Marshall, A. T.; Haverkamp, R. G. Electrocatalytic Activity of IrO(2)-RuO(2) Supported on Sb-Doped SnO(2) Nanoparticles. Electrochim. Acta 2010, 55 (6), 1978-1984.

(11) Petrykin, V.; Macounová, K.; Okube, M.; Mukerjee, S.; Krtil, P. Local Structure of Co Doped $\mathrm{RuO}_{2}$ Nanocrystalline Electrocatalytic Materials for Chlorine and Oxygen Evolution. Catal. Today 2013, 202, 63-69. 
(12) Kuznetsova, E.; Petrykin, V.; Sunde, S.; Krtil, P. Selectivity of Nanocrystalline $\mathrm{IrO}_{2}$-Based Catalysts in Parallel Chlorine and Oxygen Evolution. Electrocatalysis 2014, 6 (2), 198-210.

(13) Nong, H. N.; Gan, L.; Willinger, E.; Teschner, D.; Strasser, P. IrO ${ }_{x}$ Core-Shell Nanocatalysts for Costand Energy-Efficient Electrochemical Water Splitting. Chem. Sci. 2014, 5 (8), 2955-2963.

(14) Lebedev, D.; Povia, M.; Waltar, K.; Abdala, P. M.; Castelli, I. E.; Fabbri, E.; Blanco, M. V.; Fedorov, A.; Copéret, C.; Marzari, N.; Schmidt, T. J. Highly Active and Stable Iridium Pyrochlores for Oxygen Evolution Reaction. Chem. Mater. 2017, 29 (12), 5182-5191.

(15) Parrondo, J.; George, M.; Capuano, C.; Ayers, K. E.; Ramani, V. Pyrochlore Electrocatalysts for Efficient Alkaline Water Electrolysis. J. Mater. Chem. A 2015, 3 (20), 10819-10828.

(16) Taira, N.; Wakeshima, M.; Hinatsu, Y. Magnetic Properties of Ruthenium Pyrochlores $\mathrm{R}_{2} \mathrm{Ru}_{2} \mathrm{O}_{7}(\mathrm{R}=$ Rare Earth). J. Phys.: Condens. Matter 1999, 11 (36), 6983.

(17) Taira, N.; Wakeshima, M.; Hinatsu, Y. Magnetic Properties of Iridium Pyrochlores $R_{2} I_{2} O_{7}(R=Y$, Sm, Eu and Lu). J. Phys.: Condens. Matter 2001, 13 (23), 5527.

(18) Horowitz, H. S.; Longo, J. M.; Horowitz, H. H.; Lewandowski, J. T. The Synthesis and Electrocatalytic Properties of Nonstoichiometric Ruthenate Pyrochlores. In Solid State Chemistry in Catalysis; American Chemical Society: 1985; Chapter 9, pp 143-163.

(19) Kim, M.; Ju, H.; Kim, J. Single Crystalline $\mathrm{Bi}_{2} \mathrm{Ru}_{2} \mathrm{O}_{7}$ Pyrochlore Oxide Nanoparticles as Efficient Bifunctional Oxygen Electrocatalyst for Hybrid Na-Air Batteries. Chem. Eng. J. 2019, 358, 11-19.

(20) Sun, W.; Liu, J.-Y.; Gong, X.-Q.; Zaman, W.-Q.; Cao, L.-M.; Yang, J. Oer Activity Manipulated by IrO $_{6}$ Coordination Geometry: An Insight from Pyrochlore Iridates. Scientific Reports 2016, 6, 38429.

(21) Kim, J.; Shih, P.-C.; Tsao, K.-C.; Pan, Y.-T.; Yin, X.; Sun, C.-J.; Yang, H. High-Performance PyrochloreType Yttrium Ruthenate Electrocatalyst for Oxygen Evolution Reaction in Acidic Media. J. Am. Chem. Soc. 2017, 139 (34), 12076-12083.

(22) Shih, P.-C.; Kim, J.; Sun, C.-J.; Yang, H. Single-Phase Pyrochlore $\mathrm{Y}_{2} \mathrm{Ir}_{2} \mathrm{O}_{7}$ Electrocatalyst on the Activity of Oxygen Evolution Reaction. ACS Applied Energy Materials 2018, 1 (8), 3992-3998.

(23) Greeley, J.; Stephens, I. E. L.; Bondarenko, A. S.; Johansson, T. P.; Hansen, H. A.; Jaramillo, T. F.; Rossmeisl, J.; Chorkendorff, I.; Nørskov, J. K. Alloys of Platinum and Early Transition Metals as Oxygen Reduction Electrocatalysts. Nature Chemistry 2009, 1 (7), 552-556.

(24) Castelli, I. E.; Olsen, T.; Datta, S.; Landis, D. D.; Dahl, S.; Thygesen, K. S.; Jacobsen, K. W. Computational Screening of Perovskite Metal Oxides for Optimal Solar Light Capture. Energy \& Environmental Science 2012, 5 (2), 5814-5819.

(25) Wu, Y.; Lazic, P.; Hautier, G.; Persson, K.; Ceder, G. First Principles High Throughput Screening of Oxynitrides for Water-Splitting Photocatalysts. Energy \& Environmental Science 2013, 6 (1), 157-168. (26) Marzari, N. The Frontiers and the Challenges. Nat. Mater. 2016, 15, 381. 
(27) Lejaeghere, K.; Bihlmayer, G.; Björkman, T.; Blaha, P.; Blügel, S.; Blum, V.; Caliste, D.; Castelli, I. E.; Clark, S. J.; Dal Corso, A.; de Gironcoli, S.; Deutsch, T.; Dewhurst, J. K.; Di Marco, I.; Draxl, C.; Dułak, M.; Eriksson, O.; Flores-Livas, J. A.; Garrity, K. F.; Genovese, L.; Giannozzi, P.; Giantomassi, M.; Goedecker, S.; Gonze, X.; Grånäs, O.; Gross, E. K. U.; Gulans, A.; Gygi, F.; Hamann, D. R.; Hasnip, P. J.; Holzwarth, N. A. W.; Iuşan, D.; Jochym, D. B.; Jollet, F.; Jones, D.; Kresse, G.; Koepernik, K.; Küçükbenli, E.; Kvashnin, Y. O.; Locht, I. L. M.; Lubeck, S.; Marsman, M.; Marzari, N.; Nitzsche, U.; Nordström, L.; Ozaki, T.; Paulatto, L.; Pickard, C. J.; Poelmans, W.; Probert, M. I. J.; Refson, K.; Richter, M.; Rignanese, G.-M.; Saha, S.; Scheffler, M.; Schlipf, M.; Schwarz, K.; Sharma, S.; Tavazza, F.; Thunström, P.; Tkatchenko, A.; Torrent, M.; Vanderbilt, D.; van Setten, M. J.; Van Speybroeck, V.; Wills, J. M.; Yates, J. R.; Zhang, G.-X.; Cottenier, S. Reproducibility in Density Functional Theory Calculations of Solids. Science 2016, 351 (6280).

(28) Kim, B.-J.; Abbott, D. F.; Cheng, X.; Fabbri, E.; Nachtegaal, M.; Bozza, F.; Castelli, I. E.; Lebedev, D.; Schäublin, R.; Copéret, C.; Graule, T.; Marzari, N.; Schmidt, T. J. Unraveling Thermodynamics, Stability, and Oxygen Evolution Activity of Strontium Ruthenium Perovskite Oxide. ACS Catal. 2017, 7 (5), 32453256.

(29) Giannozzi, P.; Baroni, S.; Bonini, N.; Calandra, M.; Car, R.; Cavazzoni, C.; Ceresoli, D.; Chiarotti, G. L.; Cococcioni, M.; Dabo, I.; Corso, A. D.; Gironcoli, S. d.; Baroni, S.; Fratesi, G.; Gebauer, R.; Gerstmann, U.; Gougoussis, C.; Kokalj, A.; Lazzeri, M.; Martin-Samos, L.; Marzari, N.; Mauri, F.; Mazzarello, R.; Paolini, S.; Pasquarello, A.; Paulatto, L.; Sbraccia, C.; Scandolo, S.; Sclauzero, G.; Seitsonen P., A.; Smogunov, A.; Umari, P.; Wentzcovitch, R. M. Quantum Espresso: A Modular and Open-Source Software Project for Quantum Simulations of Materials. J. Phys.: Condens. Matter 2009, 21 (39), 395502

(30) Pizzi, G.; Cepellotti, A.; Sabatini, R.; Marzari, N.; Kozinsky, B. AlIDA: Automated Interactive Infrastructure and Database for Computational Science. Computational Materials Science 2016, 111, 218-230.

(31) Prandini, G.; Marrazzo, A.; Castelli, I. E.; Mounet, N.; Marzari, N. Precision and Efficiency in SolidState Pseudopotential Calculations. npj Computational Materials 2018, 4 (1), 72.

(32) Perdew, J. P.; Ruzsinszky, A.; Csonka, G. I.; Vydrov, O. A.; Scuseria, G. E.; Constantin, L. A.; Zhou, X.; Burke, K. Restoring the Density-Gradient Expansion for Exchange in Solids and Surfaces. Phys. Rev. Lett. 2008, 100 (13), 136406.

(33) Setyawan, W.; Curtarolo, S. High-Throughput Electronic Band Structure Calculations: Challenges and Tools. Computational Materials Science 2010, 49 (2), 299-312.

(34) Larsen, A. H.; Mortensen, J. J.; Blomqvist, J.; Castelli, I. E.; Christensen, R.; Dułak, M.; Friis, J.; Groves, M. N.; Hammer, B.; Hargus, C.; Hermes, E. D.; Jennings, P. C.; Jensen, P. B.; Kermode, J.; Kitchin, 
J. R.; Kolsbjerg, E. L.; Kubal, J.; Kaasbjerg, K.; Lysgaard, S.; Maronsson, J. B.; Maxson, T.; Olsen, T.; Pastewka, L.; Peterson, A.; Rostgaard, C.; Schiøtz, J.; Schütt, O.; Strange, M.; Thygesen, K. S.; Vegge, T.; Vilhelmsen, L.; Walter, M.; Zeng, Z.; Jacobsen, K. W. The Atomic Simulation Environment-a Python Library for Working with Atoms. J. Phys.: Condens. Matter 2017, 29 (27), 273002.

(35) Jain, A.; Ong, S. P.; Hautier, G.; Chen, W.; Richards, W. D.; Dacek, S.; Cholia, S.; Gunter, D.; Skinner, D.; Ceder, G.; Persson, K. A. Commentary: The Materials Project: A Materials Genome Approach to Accelerating Materials Innovation. APL Materials 2013, 1 (1), 011002.

(36) Johnson, J. W.; Oelkers, E. H.; Helgeson, H. C. Supcrt92: A Software Package for Calculating the Standard Molal Thermodynamic Properties of Minerals, Gases, Aqueous Species, and Reactions from 1 to 5000 Bar and 0 to $1000^{\circ} \mathrm{C}$. Computers \& Geosciences 1992, 18 (7), 899-947.

(37) Pourbaix, M. Atlas of Electrochemical Equilibria in Aqueous Solutions, NACE International: 1973.

(38) Persson, K. A.; Waldwick, B.; Lazic, P.; Ceder, G. Prediction of Solid-Aqueous Equilibria: Scheme to Combine First-Principles Calculations of Solids with Experimental Aqueous States. Physical Review $B$ 2012, 85 (23), 235438.

(39) Castelli, I. E.; Thygesen, K. S.; Jacobsen, K. W. Calculated Pourbaix Diagrams of Cubic Perovskites for Water Splitting: Stability against Corrosion. Top. Catal. 2014, 57 (1-4), 265-272.

(40) Castelli, I. E.; Hüser, F.; Pandey, M.; Li, H.; Thygesen, K. S.; Seger, B.; Jain, A.; Persson, K. A.; Ceder, G.; Jacobsen, K. W. Light-Harvesting Materials: New Light-Harvesting Materials Using Accurate and Efficient Bandgap Calculations. Advanced Energy Materials 2015, 5 (2).

(41) Petrykin, V.; Macounova, K.; Shlyakhtin, O. A.; Krtil, P. Tailoring the Selectivity for Electrocatalytic Oxygen Evolution on Ruthenium Oxides by Zinc Substitution. Angew. Chem. Int. Ed. 2010, 49 (28), 4813-4815.

(42) A. Shlyakhtin, O.; D. Tretyakov, Y. Recent Progress in Cryochemical Synthesis of Oxide Materials. J. Mater. Chem. 1999, 9 (1), 19-24.

(43) Conder, K.; Pomjakushina, E.; Soldatov, A.; Mitberg, E. Oxygen Content Determination in Perovskite-Type Cobaltates. Mater. Res. Bull. 2005, 40 (2), 257-263.

(44) Muller, O.; Nachtegaal, M.; Just, J.; Lutzenkirchen-Hecht, D.; Frahm, R. Quick-EXAFS Setup at the SuperXAS Beamline for in Situ X-Ray Absorption Spectroscopy with $10 \mathrm{~ms}$ Time Resolution. J. Synchrotron Rad. 2016, 23 (1), 260-266.

(45) Ravel, B.; Newville, M. Athena, Artemis, Hephaestus: Data Analysis for X-Ray Absorption Spectroscopy Using IFEFFIT. J. Synchrotron Rad. 2005, 12 (4), 537-541.

(46) Newville, M. IFEFFIT : Interactive XAFS Analysis and FEFF Fitting. J. Synchrotron Rad. 2001, 8, 322324. 
(47) Schmidt, T. J.; Gasteiger, H. A.; Stäb, G. D.; Urban, P. M.; Kolb, D. M.; Behm, R. J. Characterization of High-Surface-Area Electrocatalysts Using a Rotating Disk Electrode Configuration. J. Electrochem. Soc. 1998, 145 (7), 2354-2358.

(48) Jirkovský, J.; Hoffmannova, H.; Klementova, M.; Krtil, P. Particle Size Dependence of the Electrocatalytic Activity of Nanocrystalline $\mathrm{RuO}_{2}$ Electrodes. J. Electrochem Soc. 2006, 153, E111-E118. (49) Sun, W.; Dacek, S. T.; Ong, S. P.; Hautier, G.; Jain, A.; Richards, W. D.; Gamst, A. C.; Persson, K. A.; Ceder, G. The Thermodynamic Scale of Inorganic Crystalline Metastability. Science Advances 2016, 2 (11), e1600225.

(50) Donnerer, C.; Rahn, M. C.; Sala, M. M.; Vale, J. G.; Pincini, D.; Strempfer, J.; Krisch, M.; Prabhakaran, D.; Boothroyd, A. T.; McMorrow, D. F. All-in--All-out Magnetic Order and Propagating Spin Waves in $\mathrm{Sm}_{2} \mathrm{Ir}_{2} \mathrm{O}_{7}$. Phys. Rev. Lett. 2016, 117 (3), 037201.

(51) Stoerzinger, K. A.; Diaz-Morales, O.; Kolb, M.; Rao, R. R.; Frydendal, R.; Qiao, L.; Wang, X. R.; Halck, N. B.; Rossmeisl, J.; Hansen, H. A.; Vegge, T.; Stephens, I. E. L.; Koper, M. T. M.; Shao-Horn, Y. Orientation-Dependent Oxygen Evolution on $\mathrm{RuO}_{2}$ without Lattice Exchange. ACS Energy Letters 2017, $2(4), 876-881$.

(52) Man, I. C.; Su, H.-Y.; Calle-Vallejo, F.; Hansen, H. A.; Martínez, J. I.; Inoglu, N. G.; Kitchin, J.; Jaramillo, T. F.; Nørskov, J. K.; Rossmeisl, J. Universality in Oxygen Evolution Electrocatalysis on Oxide Surfaces. ChemCatChem 2011, 3 (7), 1159-1165.

(53) Rossell, H. J. Fluorite-Related Phases $\mathrm{Ln}_{3} \mathrm{MO}_{7}$, $\mathrm{Ln}=$ Rare Earth, $\mathrm{Y}$ or Sc, $\mathrm{M}=\mathrm{Nb}$, Sb, or Ta: ii. Structure Determination. J. Solid State Chem. 1979, 27 (1), 115-122.

(54) Banerjee, A.; Chaudhary, Z. S. The System Yb-Ru-O: High Temperature Studies on the Oxides $\mathrm{Yb}_{2} \mathrm{Ru}_{2} \mathrm{O}_{7}(\mathrm{~s})$ and $\mathrm{Yb}_{3} \mathrm{RuO}_{7}(\mathrm{~s})$. Mater. Chem. Phys. 2013, 142 (1), 12-16.

(55) Schneider, S. J.; Waring, J. L.; Tressler, R. E. Phase Relations between Iridium and the Sesquioxides in Air. J. Res. Natl. Bur. Stand. Sect. A. Phys. Chem. 1965, 69A, 245-54.

(56) Sleight, A. W.; Ramirez, A. P. Disappearance of the Metal-Insulator Transition in Iridate Pyrochlores on Approaching the Ideal $\mathrm{R}_{2} \mid \mathrm{I}_{2} \mathrm{O}_{7}$ Stoichiometry. Solid State Commun. 2018, 275, 12-15.

(57) Riegg, S.; Reller, A.; Loidl, A.; Ebbinghaus, S. G. Valence Properties of $\mathrm{Cu}$ and Ru in TitaniumSubstituted $\mathrm{LnCu}_{3} \mathrm{Ru}_{4} \mathrm{O}_{12+\Delta}(\mathrm{Ln}=\mathrm{La}, \mathrm{Pr}, \mathrm{Nd})$ Investigated by XANES and TGA. Dalton Transactions 2015, 44 (23), 10852-10859.

(58) Kennedy, B. J. Structural Trends in Pyrochlore-Type Oxides. Physica B: Condensed Matter 1997, 241-243, 303-310.

(59) Doyle, R. L.; Godwin, I. J.; Brandon, M. P.; Lyons, M. E. G. Redox and Electrochemical Water Splitting Catalytic Properties of Hydrated Metal Oxide Modified Electrodes. PCCP 2013, 15 (33), 1373713783. 
(60) ten Kortenaar, M. V.; Vente, J. F.; ljdo, D. J. W.; Müller, S.; Kötz, R. Oxygen Evolution and Reduction on Iridium Oxide Compounds. J. Power Sources 1995, 56 (1), 51-60.

(61) Seitz, L. C.; Dickens, C. F.; Nishio, K.; Hikita, Y.; Montoya, J.; Doyle, A.; Kirk, C.; Vojvodic, A.; Hwang, H. Y.; Norskov, J. K.; Jaramillo, T. F. A Highly Active and Stable $\mathrm{IrO}_{x}-\mathrm{SrIrO}_{3}$ Catalyst for the Oxygen Evolution Reaction. Science 2016, 353 (6303), 1011-1014.

(62) Grimaud, A.; Demortière, A.; Saubanère, M.; Dachraoui, W.; Duchamp, M.; Doublet, M.-L.; Tarascon, J.-M. Activation of Surface Oxygen Sites on an Iridium-Based Model Catalyst for the Oxygen Evolution Reaction. Nature Energy 2016, 2, 16189.

(63) Gardner, J. S.; Gingras, M. J. P.; Greedan, J. E. Magnetic Pyrochlore Oxides. Reviews of Modern Physics 2010, 82 (1), 53-107.

(64) Binninger, T.; Mohamed, R.; Waltar, K.; Fabbri, E.; Levecque, P.; Kötz, R.; Schmidt, T. J. Thermodynamic Explanation of the Universal Correlation between Oxygen Evolution Activity and Corrosion of Oxide Catalysts. Sci. Rep. 2015, 5, 12167.

(65) Fabbri, E.; Schmidt, T. J. Oxygen Evolution Reaction-the Enigma in Water Electrolysis. ACS Catal. 2018, 8 (10), 9765-9774.

(66) Wohlfahrt-Mehrens, M.; Heitbaum, J. Oxygen Evolution on $\mathrm{Ru}$ and $\mathrm{RuO}_{2}$ Electrodes Studied Using Isotope Labelling and On-Line Mass Spectrometry. Journal of Electroanalytical Chemistry and Interfacial Electrochemistry 1987, 237 (2), 251-260.

(67) Macounova, K.; Makarova, M.; Krtil, P. Oxygen Evolution on Nanocrystalline $\mathrm{RuO}_{2}$ and $\mathrm{Ru}_{0.9} \mathrm{Ni}_{0.1} \mathrm{O}_{2-\Delta}$ Electrodes - DEMS Approach to Reaction Mechanism Determination. Electrochem. Commun. 2009, 11 (10), 1865-1868.

(68) Fierro, S.; Nagel, T.; Baltruschat, H.; Comninellis, C. Investigation of the Oxygen Evolution Reaction on $\mathrm{Ti} / \mathrm{IrO}_{2}$ Electrodes Using Isotope Labelling and On-Line Mass Spectrometry. Electrochem. Commun. 2007, 9 (8), 1969-1974.

(69) Rong, X.; Parolin, J.; Kolpak, A. M. A Fundamental Relationship between Reaction Mechanism and Stability in Metal Oxide Catalysts for Oxygen Evolution. ACS Catal. 2016, 6 (2), 1153-1158.

(70) Fabbri, E.; Nachtegaal, M.; Binninger, T.; Cheng, X.; Kim, B.-J.; Durst, J.; Bozza, F.; Graule, T.; Schäublin, R.; Wiles, L.; Pertoso, M.; Danilovic, N.; Ayers, K. E.; Schmidt, T. J. Dynamic Surface SelfReconstruction Is the Key of Highly Active Perovskite Nano-Electrocatalysts for Water Splitting. Nat. Mater. 2017, 16, 925-931. 
a.

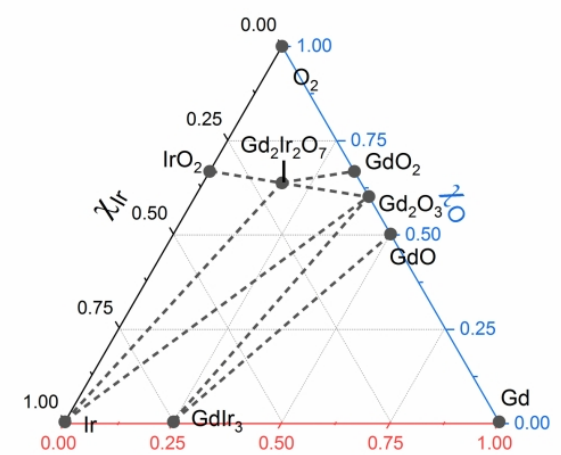

C.

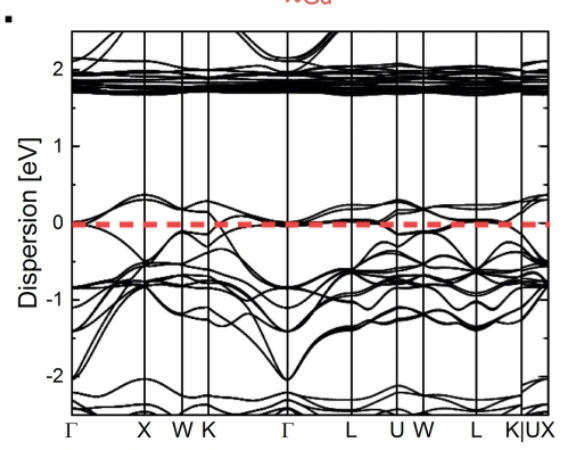

b.

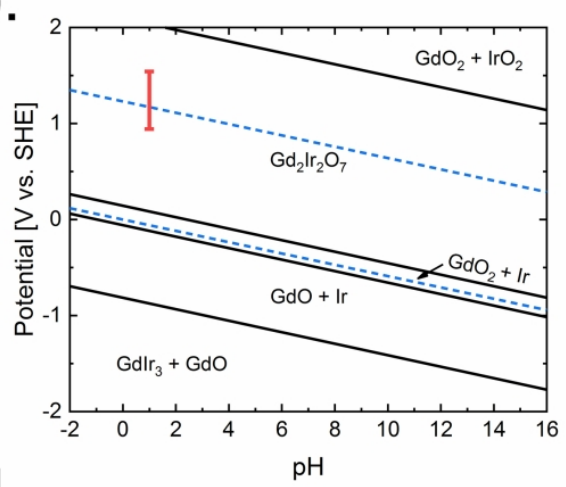

d.

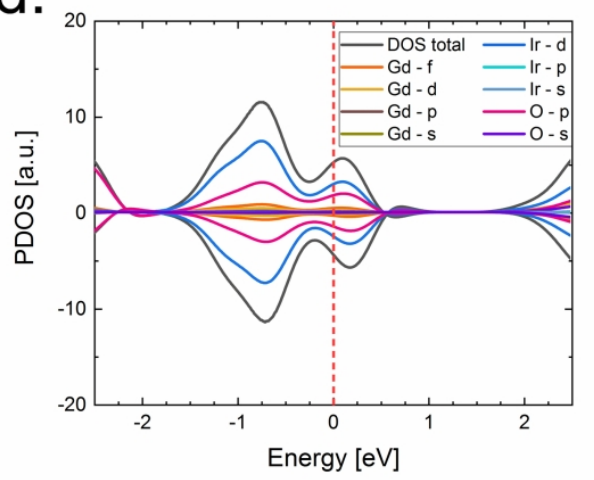

Figure 1. The (a) phase diagram, (b) Pourbaix diagram, (c) band structure diagram, and (d) PDOS diagram for $\mathrm{Gd}_{2} \mathrm{Ir}_{2} \mathrm{O}_{7}$. The Fermi level is indicated by the dashed red lines in the band structure and PDOS diagrams. The dashed blue lines in the Pourbaix diagram indicate the water redox potentials, while the solid red bar indicates the operating $\mathrm{E}-\mathrm{pH}$ window examined in this study.

$253 \times 201 \mathrm{~mm}(300 \times 300$ DPI $)$ 


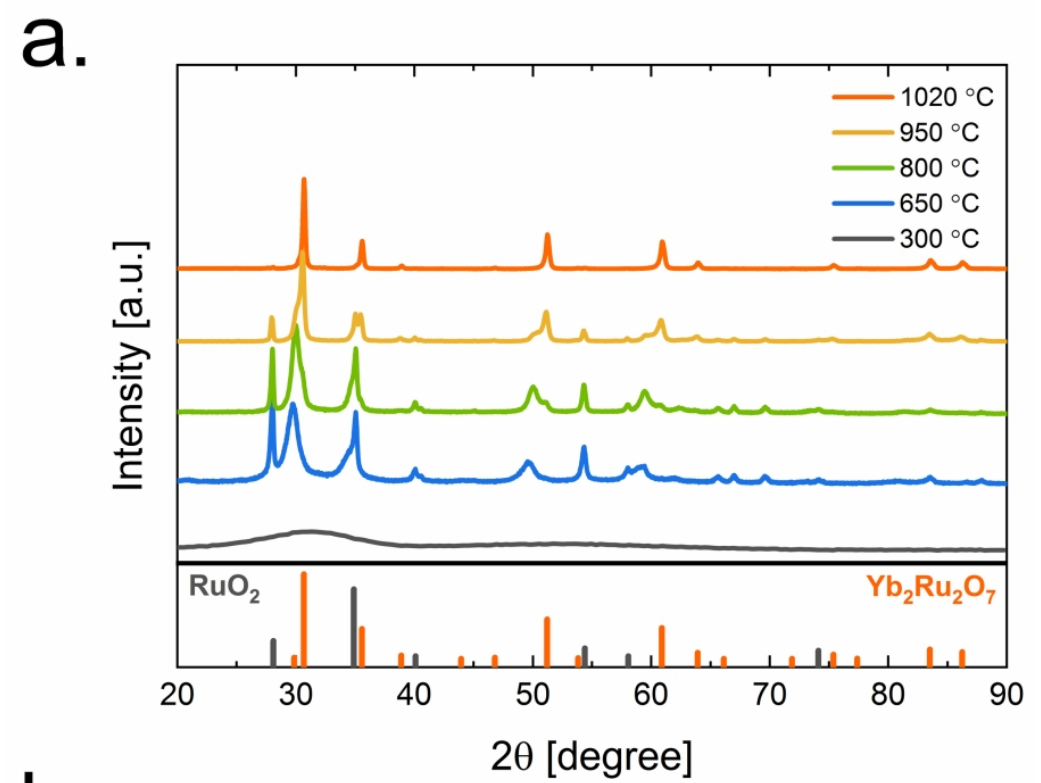

b.

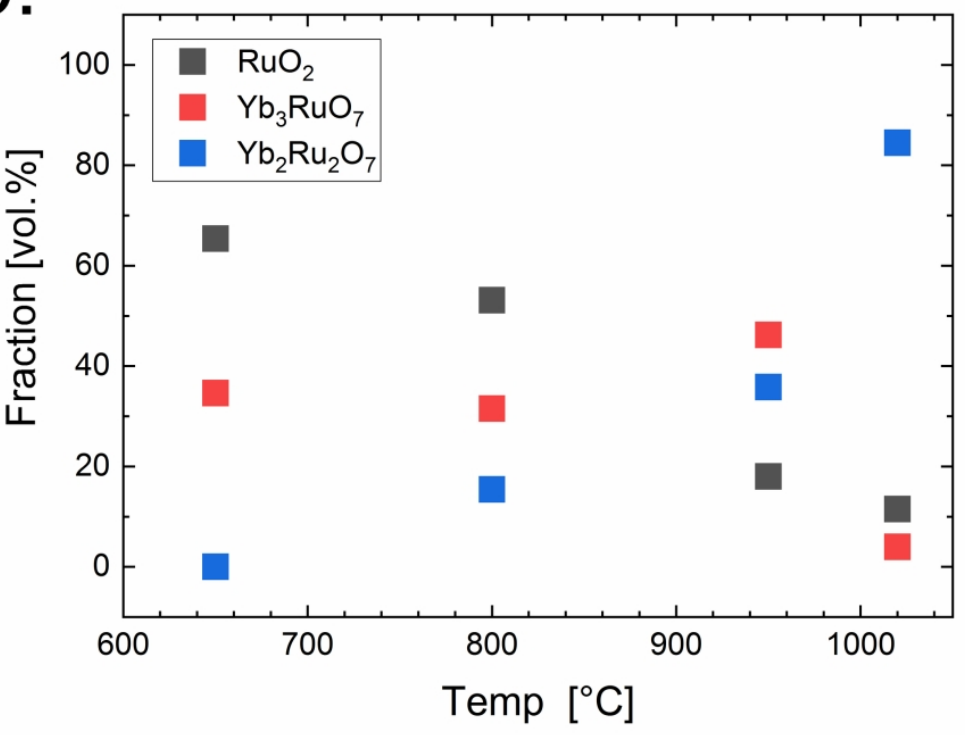

Figure 2. (a) X-ray diffraction patterns of the spray freeze-freeze-dried precursor of the aggregate composition $\mathrm{Yb}_{2} \mathrm{Ru}_{2} \mathrm{O}_{7}$ annealed at different temperatures in air; and (b) phase composition of the sprayfreeze freeze-dried precursor corresponding to the aggregate chemical composition $\mathrm{Yb}_{2} \mathrm{Ru}_{2} \mathrm{O}_{7}$ annealed at different temperatures.

$188 \times 285 \mathrm{~mm}(300 \times 300 \mathrm{DPI})$ 

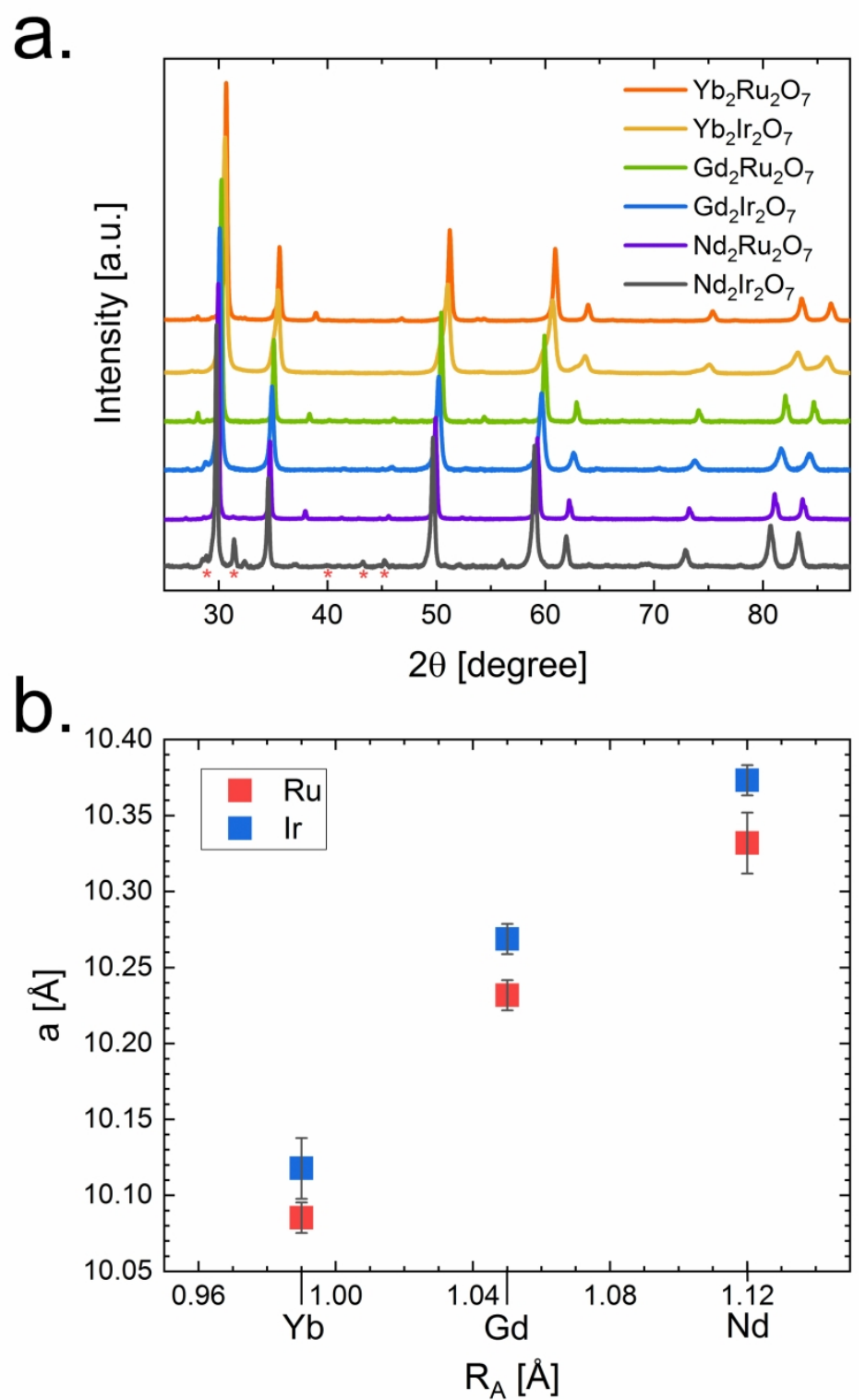

Figure 3. (a) X-ray diffraction patterns of the Ru and Ir-based pyrochlores annealed at $1020^{\circ} \mathrm{C}$ for 4 hours. The formation of $\mathrm{Nd}_{2} \mathrm{Ru}_{2} \mathrm{O}_{7}$ is accompanied by a simultaneous formation of $\mathrm{Nd}_{6} \mathrm{Ir}_{2} \mathrm{O}_{13}$ (orange asterisks) ${ }^{83}$ and (b) unit cell parameters of the Ru and Ir pyrochlores as a function of the rare-earth metal cation. $179 \times 298 \mathrm{~mm}(300 \times 300$ DPI $)$ 

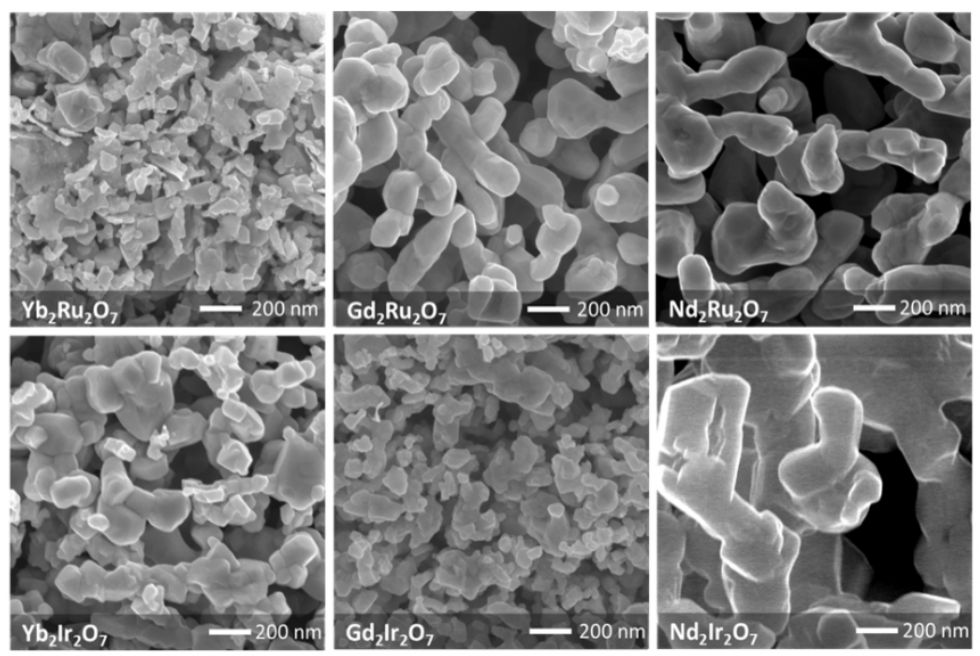

\begin{tabular}{|l|l|}
\hline Sample & $\begin{array}{l}\text { Diameter } \\
\text { [nm] }\end{array}$ \\
\hline $\mathrm{Yb}_{2} \mathrm{Ru}_{2} \mathrm{O}_{7}$ & $83 \pm 11$ \\
\hline $\mathrm{Gd}_{2} \mathrm{Ru}_{2} \mathrm{O}_{7}$ & $173 \pm 12$ \\
\hline $\mathrm{Nd}_{2} \mathrm{Ru}_{2} \mathrm{O}_{7}$ & $350 \pm 12$ \\
\hline $\mathrm{Yb}_{2} \mathrm{Ir}_{2} \mathrm{O}_{7}$ & $156 \pm 9$ \\
\hline $\mathrm{Gd}_{2} \mathrm{Ir}_{2} \mathrm{O}_{7}$ & $142 \pm 5$ \\
\hline $\mathrm{Nd}_{2} \mathrm{Ir}_{2} \mathrm{O}_{7}$ & $348 \pm 23$ \\
\hline
\end{tabular}

statistical analysis of size distribution from 400 to 1000 particles.

Figure 4. SEM micrographs depicting the morphologies of the Ru and Ir-based pyrochlores prepared by the spray-freeze freeze-drying approach with subsequent annealing at $1020^{\circ} \mathrm{C}$ for 4 hours.

$208 \times 105 \mathrm{~mm}(150 \times 150 \mathrm{DPI})$ 
a.

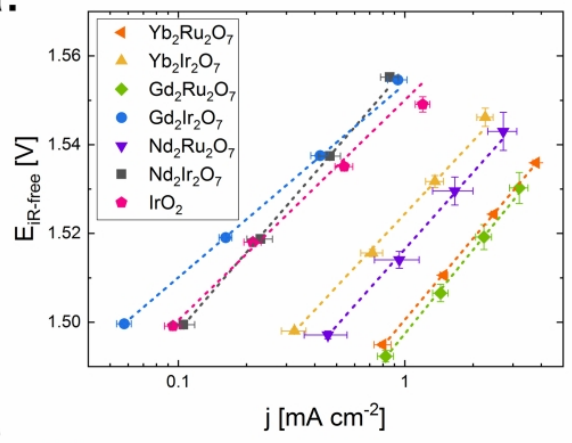

C.

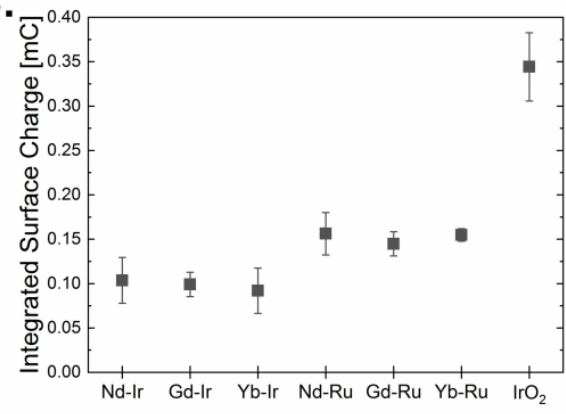

b.

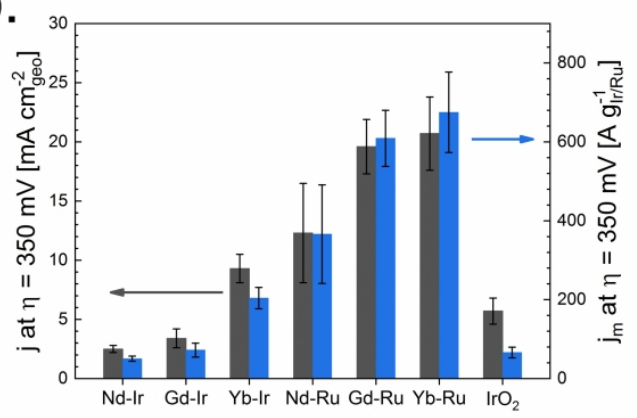

d.

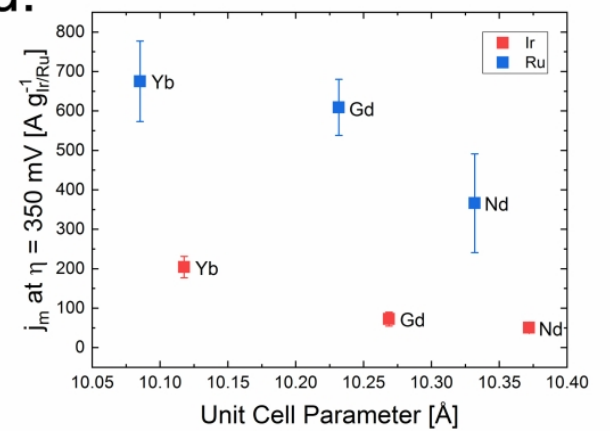

Figure 5. (a) Tafel plots of the oxygen evolution on nanoparticulate Ru and Ir-based pyrochlore catalysts extracted from steady-state chronoamperometric measurements in $0.1 \mathrm{M} \mathrm{HClO}_{4}$, (b) measured OER activities for the prepared pyrochlore series, (c) surface charge of the pyrochlore samples as calculated from cyclic voltammograms (average integration of anodic and cathodic scans) measured between 1.0 and $1.4 \mathrm{~V}$ vs. RHE (Note: CVs were recorded before and after the steady-state polarization measurements shown in panel (a)), and (d) the average specific activity of the Ru and Ir pyrochlores as a function of the unit cell parameter. Activity data for $\mathrm{IrO}_{2}$ was previously reported in references 16, 25.

$289 \times 202 \mathrm{~mm}(300 \times 300$ DPI $)$ 

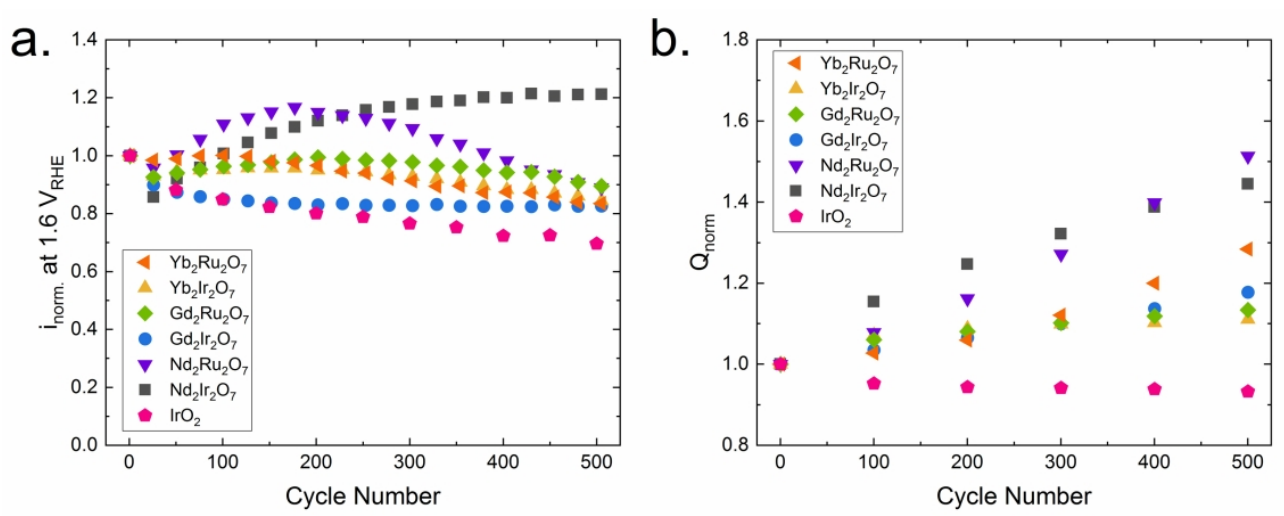

Figure 6. Electrochemical stability measurements for the pyrochlore samples showing the normalized current density at $1.6 \mathrm{~V}_{\mathrm{RHE}}(\mathrm{a})$ and the normalized surface charge calculated from cyclic voltammograms recorded after every 100 potential-step cycles (b) as a function of potential-step cycle number. Stability data for $\mathrm{IrO}_{2}$ was previously reported in references 16, 25.

$275 \times 111 \mathrm{~mm}(300 \times 300 \mathrm{DPI})$ 

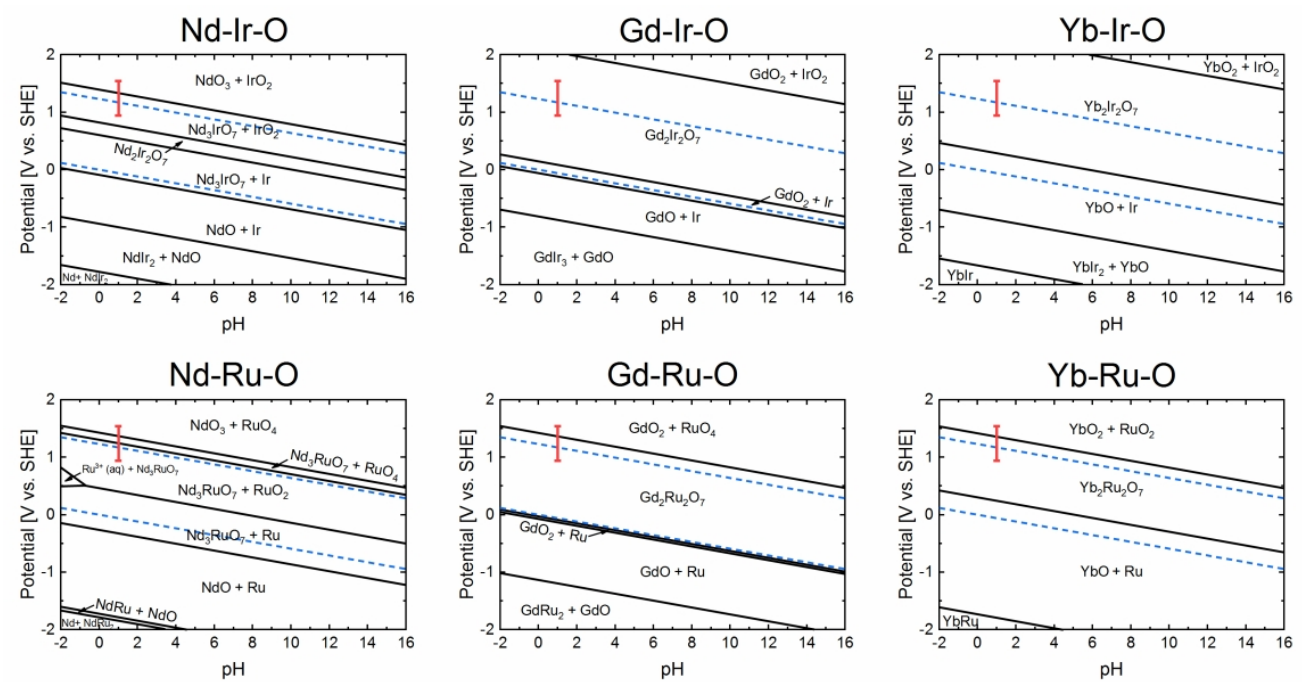

Figure 7. DFT-calculated Pourbaix diagrams for synthesized rare-earth pyrochlore series. The dotted blue lines indicate the thermodynamic redox potentials within which water is stable. The red bar at $\mathrm{pH}=1$ indicates the operating potential range examined in this study (i.e. 1.0 to $1.6 \mathrm{~V}$ vs. RHE).

$280 \times 146 \mathrm{~mm}(300 \times 300 \mathrm{DPI})$ 

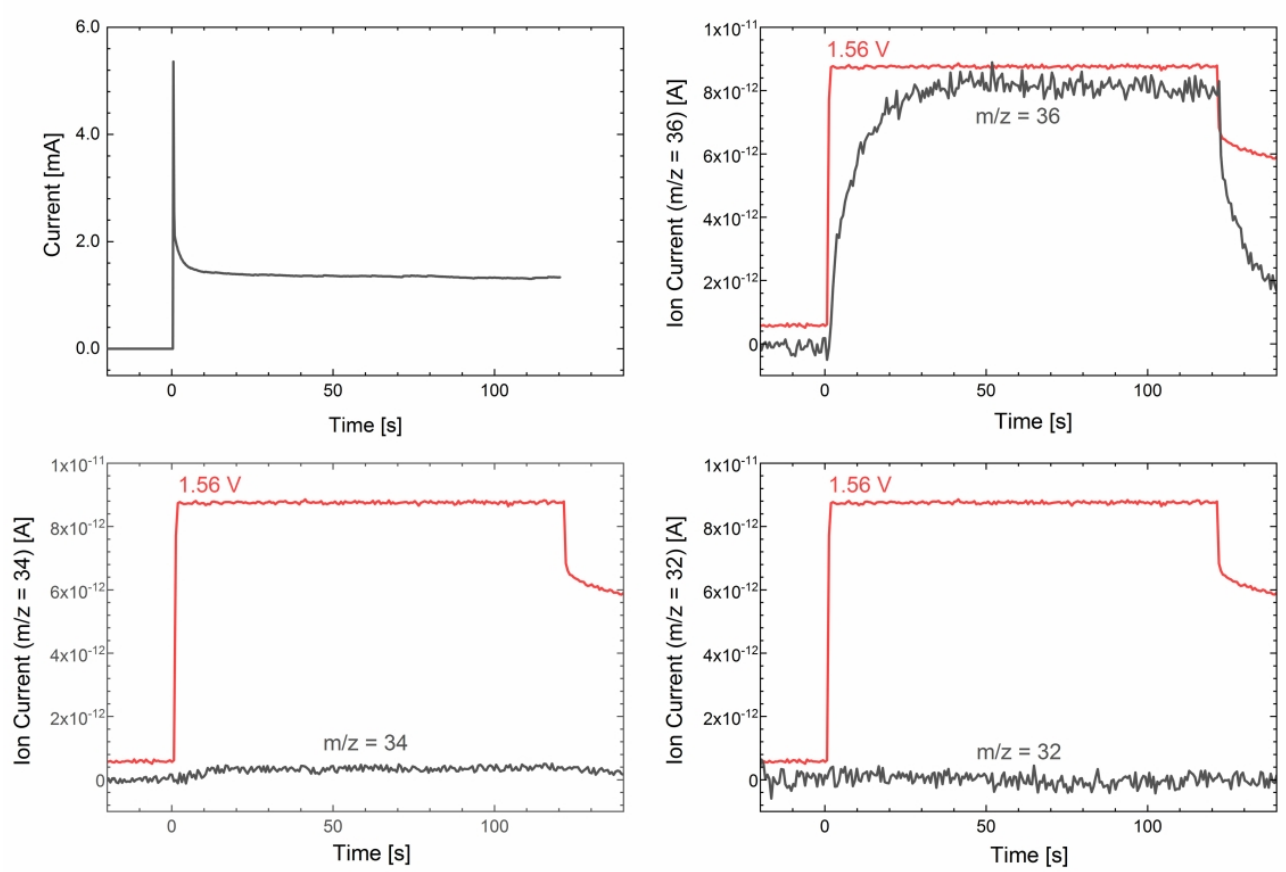

Figure 8. Electrochemical current and DEMS signal (ion current) evolved on $\mathrm{Gd}_{2} \mathrm{Ru}_{2} \mathrm{O}_{7}$ for mass fragments $\mathrm{m} / \mathrm{z}$ corresponding to oxygen of different isotope composition: $36\left({ }^{18} \mathrm{O}_{2}\right), 34\left({ }^{18} \mathrm{O}^{16} \mathrm{O}\right)$, and $32\left({ }^{16} \mathrm{O}_{2}\right)$. The recorded potential step signal is shown in red $(1.56 \mathrm{~V})$.

$307 \times 206 \mathrm{~mm}(300 \times 300$ DPI $)$ 

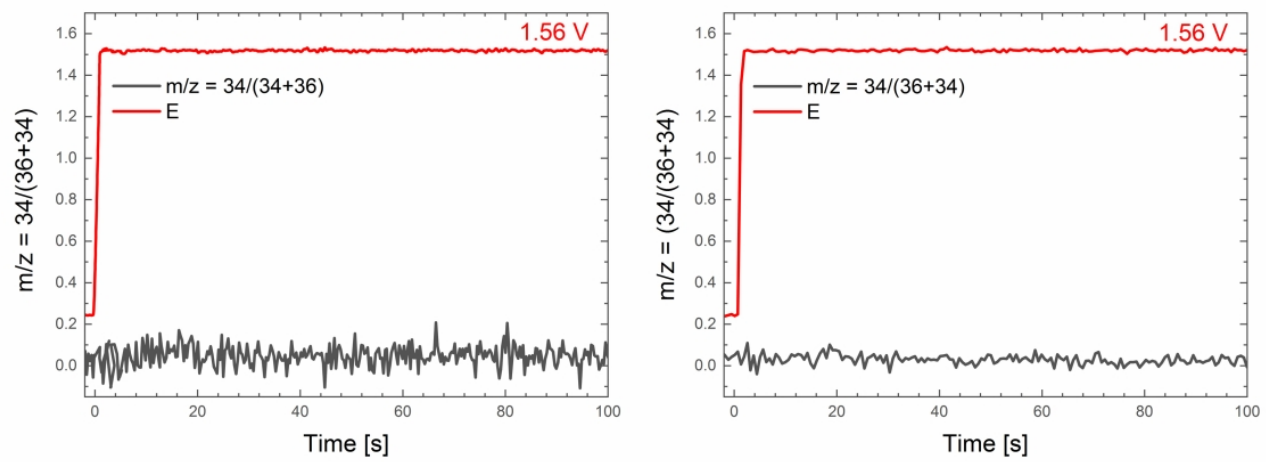

Figure 9. Fraction of $\mathrm{m} / \mathrm{z} 34$ produced during potential step experiment with ${ }^{18} \mathrm{O}$-labeled $0.1 \mathrm{M} \mathrm{HClO}_{4}$ at a potential of $1.56 \mathrm{~V}$ vs. RHE on $\mathrm{Yb}_{2} \mathrm{Ru}_{2} \mathrm{O}_{7}$ (left) and $\mathrm{Gd}_{2} \mathrm{Ru}_{2} \mathrm{O}_{7}$ (right).

$292 \times 107 \mathrm{~mm}(300 \times 300 \mathrm{DPI})$ 

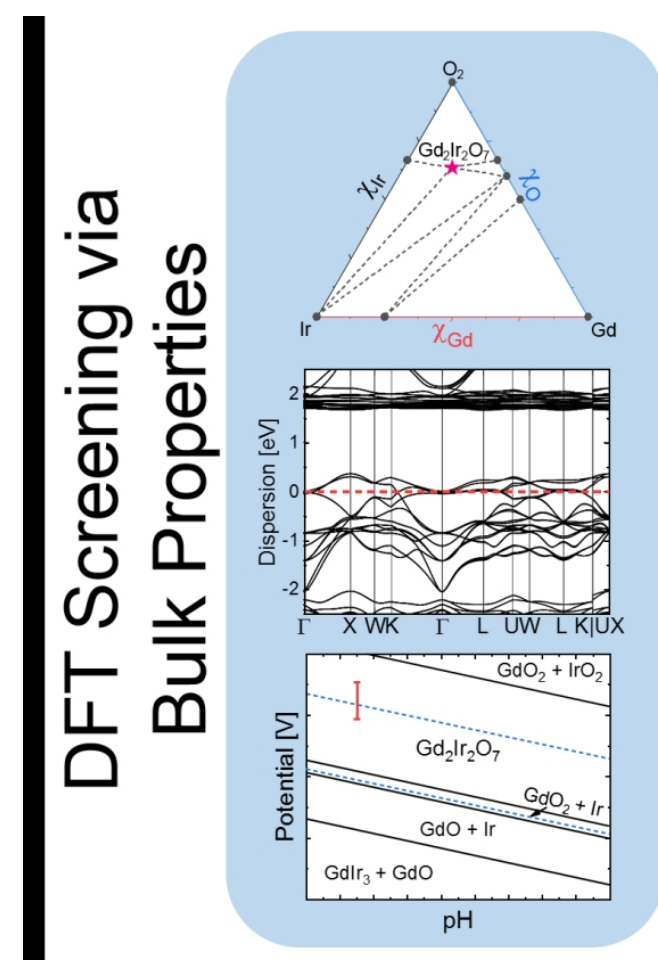

\section{OER Catalyst Synthesis}

TOC Figure

$262 \times 190 \mathrm{~mm}(150 \times 150$ DPI $)$ 